\title{
The Development of Filler Morphology in Dental Resin Composites: A Review
}

\author{
Jiani Liu ${ }^{1,2,+} \oplus$, Hao Zhang ${ }^{1, \dagger}$, Huijun Sun ${ }^{3}$, Yanru Liu ${ }^{1}$, Wenlin Liu ${ }^{1}$, Bo Su ${ }^{3}{ }^{\circledR}$ and Shibao Li ${ }^{1, *}$ \\ 1 State Key Laboratory of Military Stomatology and National Clinical Research Center for Oral Diseases, \\ Department of Dental Materials, School of Stomatology, The Fourth Military Medical University, \\ Xi'an 710032, China; Jenny170219@163.com (J.L.); ly_zhanghao@sina.cn (H.Z.); feier_22991@163.com (Y.L.); \\ liuwenlin0903@163.com (W.L.) \\ 2 The Affiliated Hospital of Stomatology, School of Stomatology, Zhejiang University School of Medicine, \\ Key Laboratory of Oral Biomedical Research of Zhejiang Province, Hangzhou 310006, China \\ 3 Bristol Dental School, University of Bristol, Lower Maudlin Street, Bristol BS1 2LY, UK; \\ iu20210@bristol.ac.uk (H.S.); B.Su@bristol.ac.uk (B.S.) \\ * Correspondence: lishibao_1974@163.com \\ + Equal contribution.
}

Citation: Liu, J.; Zhang, H.; Sun, H.; Liu, Y.; Liu, W.; Su, B.; Li, S. The Development of Filler Morphology in Dental Resin Composites: A Review. Materials 2021, 14, 5612. https:// doi.org/10.3390/ma14195612

Academic Editor: Alessandro Vichi

Received: 28 July 2021

Accepted: 23 September 2021

Published: 27 September 2021

Publisher's Note: MDPI stays neutral with regard to jurisdictional claims in published maps and institutional affiliations.

Copyright: (c) 2021 by the authors. Licensee MDPI, Basel, Switzerland. This article is an open access article distributed under the terms and conditions of the Creative Commons Attribution (CC BY) license (https:// creativecommons.org/licenses/by/ $4.0 /)$.

\begin{abstract}
Dental resin composites (DRCs) with diverse fillers added are widely-used restorative materials to repair tooth defects. The addition of fillers brings an improvement in the mechanical properties of DRCs. In the past decade, diverse fillers have emerged. However, the change of emerging fillers mainly focuses on the chemical composition, while the morphologic characteristics changes are often ignored. The fillers with new morphologies not only have the advantages of traditional fillers (particles, fibrous filler, etc.), but also endow some additional functional characteristics (stronger bonding ability to resin matrix, polymerization resistance, and wear resistance, drug release control ability, etc.). Moreover, some new morphologies are closely related to the improvement of traditional fillers, porous filler vs. glass particles, core-sheath fibrous vs. fibrous, etc. Some other new morphology fillers are combinations of traditional fillers, UHA vs. HA particles and fibrous, tetrapod-like whisker vs. whisker and fibrous filler, mesoporous silica vs. porous and silica particles. In this review, we give an overall description and a preliminary summary of the fillers, as well as our perspectives on the future direction of the development of novel fillers for next-generation DRCs.
\end{abstract}

Keywords: dental resin composite; filler morphology; particulate fillers; fibrous fillers; novel-shaped fillers; mechanical properties; surface treatment

\section{Introduction}

Dental resin composites (DRCs) have become the most popular filling material in direct dental restorations while amalgam restorations have been gradually eliminated in clinical use due to negative effects, such as having a mismatched appearance with natural teeth, potential toxicity, and environmental pollution [1]. The excellent mechanical and aesthetic properties of DRCs help them meet the demands of daily chewing and aesthetic appearance in terms of tooth color [2,3]. In addition, with corresponding adhesive systems, the composites bond to tooth tissues without the need for extensive preparation of the dental cavity, avoiding the need for excessive removal of healthy dental tissues, which is common in the case of dental amalgam [4,5]. Thus, DRCs have attracted great interest in both scientific research and clinical practice.

DRCs have three main components: resin matrix which is a mixture of monomers (20-30 wt\%); fillers(70-80 wt\%); and a small amount of catalyst or initiator [6]. After curing, the resin matrix forms a three-dimensional network structure to encapsulate fillers. And fillers have usually been treated with a coupling agent to improve the bonding and stress transfer between fillers and the matrix [7]. Since DRC shrinkage after curing seems to result 
from resin matrix polymerization, much research has focused on the modification of the resin matrix. Various types of resin matrixes have been explored to attain specific properties, e.g., low polymerization shrinkage [8], antibacterial and/or fluoride release [9], and biosafety [10]. While fillers, mainly acting as reinforcement, occupy the largest weight ratio in DRCs (about 70-80 $\mathrm{wt} \%$ ), they are surrounded by a cured resin matrix for preventing crack propagation in the event of fracture, changing the failure mode of the resin matrix after curing [11]. Fillers should have good stability and mechanical properties to ensure good final composites properties [2]. The application of fillers has already proved to be successful in many commercial and laboratory DRCs. DRCs are often named after the type of fillers, such as microfill DRCs, hybrid DRCs, micro-hybrid DRCs, and nanofill and nanohybrid DRCs, a convention adopted in the early days of their development [12-14].

Compared with the active research on resin matrixes, the research on fillers is far from sufficient, which may be because of the theory that shrinkage due to resin matrix polymerization is the main cause of failed DRC restorations. There is a preconception about fillers that their size, distribution, and chemical composition have more influence on the polishing and mechanical performance of DRCs and less on volume shrinkage [15]. A recent review on DRC fillers systematically discussed fillers based on their chemical composition and classification [16]. However, even with the same chemical composition, there are dramatic differences in the final properties of DRCs with different morphologies of fillers, especially for some novel-shaped fillers reported in recent years, such as core-sheath structure fillers and tetrapod-like fillers [17-23]. Therefore, it is insufficient to classify different forms of fillers and gauge trends in their development by only considering their chemical compositions. In addition, we found that fillers with certain special morphological features could reduce polymerization shrinkage through their spatial structure [24]. This may lead to an important breakthrough in the development of future DRCs. However, studies on filler morphologies are scattered across individual studies, and a systematic review of fillers based on morphology appears to be absent.

Here, we introduce a unique integrated classification based on filler morphologies to describe filler types and their development trends. Traditionally, the aspect ratio is an important parameter and one of the most important characteristics of fillers. Under this concept, we set the aspect ratio of 10 as a line of demarcation and classify fillers into two categories, i.e., particulate fillers (with an aspect ratio $\leq 10$ ) and fibrous fillers (with an aspect ratio $>10$ ). In addition, we propose a third category, i.e., novel-shaped fillers. This category contains either derivatives of traditional morphologies for which it is difficult to accurately determined their aspect ratios, such as bionic sea urchins, or some novel morphologies similar to traditional ones in appearance but completely different in microstructure, such as microspheres with mesoporous, hollow, or core-sheath microstructures.

\section{Filler Type Classification by Morphology}

Dimensionally, fillers can be classified into micro- and nano-scale fillers. Geometrically, they can be classified into particulate, fibrous, and novel-shaped fillers. Particulate fillers include ground quartz powder, ground glass powder, colloidal silica nanopowder, hydroxyapatite (HA) powder, and pre-polymerized powder. Fibrous fillers include microwhiskers, short glass microfiber, ceramic nanofiber, polymer nanofiber, and nanotube. Novel-shaped fillers include porous and mesoporous powder, urchin-like hydroxyapatite (UHA) powder, nanocluster powder, tetrapod-like whisker, core-sheath fiber, glass flake, and microcapsule. The classification of fillers is listed in Figure 1. 


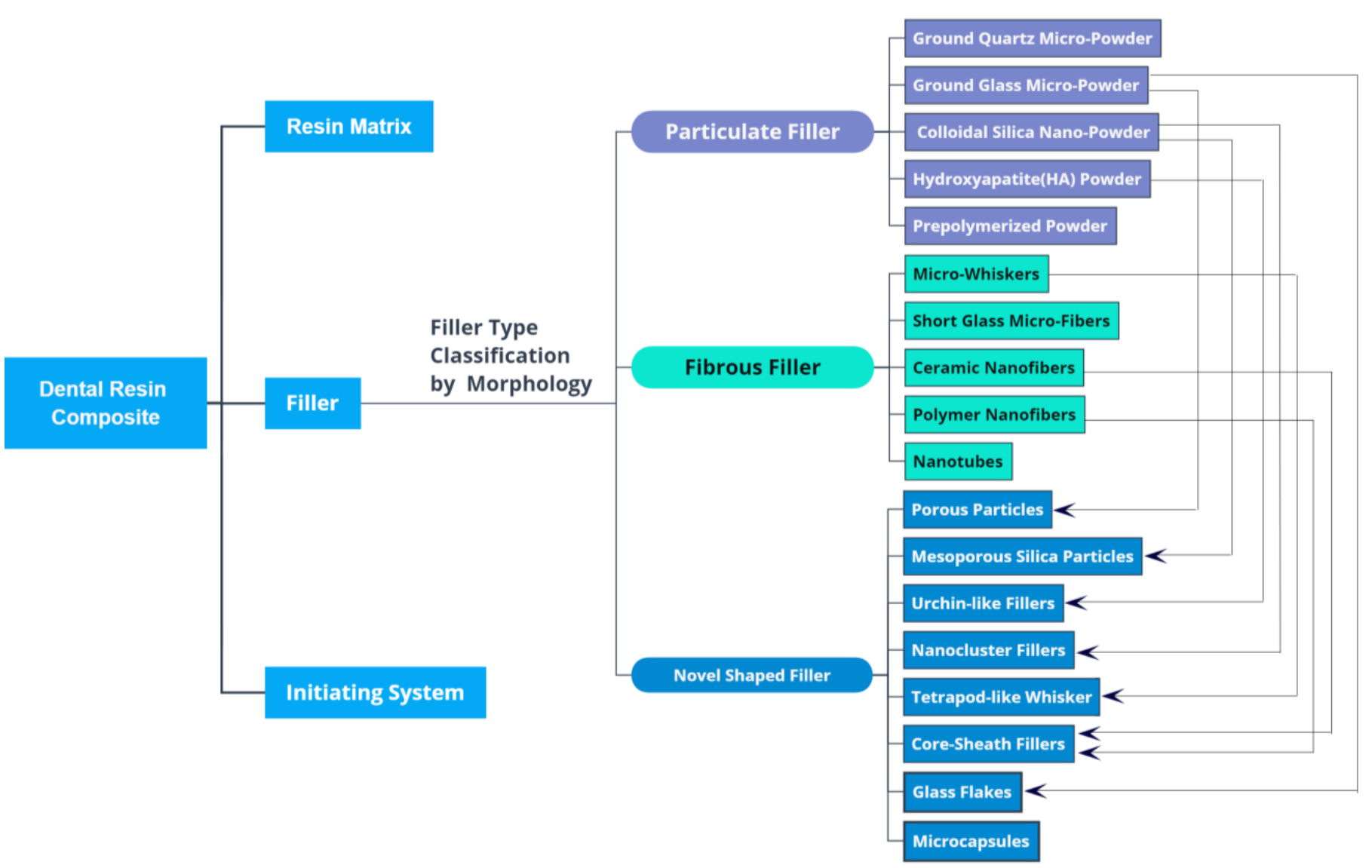

Figure 1. Classification of fillers in dental resin composites. The arrows illustrate the potential interconnections between traditional fillers and novel-shaped fillers.

\section{Particulate Fillers and Their Development}

Particulate fillers most widely used in DRCs include ground quartz micropowder, ground glass micropowder, colloidal silica nanopowder, and pre-polymerized powder [25-28]. Although HA particles are used because of their bioactivity, they have been less frequently used in DRCs. The particulate fillers and details of their properties and application in commercial composites are listed in Table 1.

Table 1. Particulate fillers for dental resin composites ${ }^{a}$.

\begin{tabular}{|c|c|c|c|c|}
\hline Filler Types & Chemical Composition & $\begin{array}{l}\text { Size } \\
(\mu \mathrm{m})\end{array}$ & Shape & Commercial Composites \\
\hline $\begin{array}{l}\text { Ground quartz } \\
\text { micropowder }\end{array}$ & $\mathrm{SiO}_{2}$ & $10-50$ & Irregular & $\begin{array}{l}\text { Aelite Aesthetic Enamel } \\
\text { (Bisco) }\end{array}$ \\
\hline $\begin{array}{l}\text { Ground glass } \\
\text { micropowder }\end{array}$ & $\mathrm{SiO}_{2}+\mathrm{BaO}+\mathrm{SrO}_{2}+\mathrm{TiO}_{2}$ & $0.6-10$ & Irregular & $\begin{array}{c}\text { Admira (Voco) } \\
\text { Artemis (Ivoclarvivadent) }\end{array}$ \\
\hline $\begin{array}{l}\text { Air colloid silica } \\
\text { ultra-fine nanopowder }\end{array}$ & $\mathrm{SiO}_{2}$ & $0.04-0.4$ & Spherical & $\begin{array}{c}\text { Enamel Plus HFO } \\
\text { (Micerium) } \\
\text { Fitek Supreme (3M ESPE) }\end{array}$ \\
\hline $\begin{array}{l}\text { Hydroxyapatite } \\
\text { particle (HA) }\end{array}$ & $\mathrm{Ca}_{5}\left(\mathrm{PO}_{4}\right)_{3}(\mathrm{OH})$ & N.I. ${ }^{b}$ & Irregular & N.I. \\
\hline $\begin{array}{l}\text { Prepolymerization } \\
\text { particle }\end{array}$ & $\mathrm{SiO}_{2}+$ resin matrix & $0.04+(0.6-1.0)$ & Spherical + irregular & $\begin{array}{c}\text { Clearfil Majesty (Kuraray) } \\
\text { TerticEvoCeram (Ivoclar } \\
\text { North America) }\end{array}$ \\
\hline
\end{tabular}

${ }^{a}$ All dental resin composites listed here include hybrid fillers instead of single fillers. ${ }^{b}$ N.I. $=$ Not informed. Information regarding the commercial composite has not been found. 


\subsection{Ground Quartz Micropowder}

Quartz is mainly composed of crystallized $\mathrm{SiO}_{2}$. Ground quartz micropowder has a large particle size (approximately 10-50 $\mu \mathrm{m}$ ), rough surface, and irregular shape. DRC with a small portion of these fillers has superior mechanical properties to pure resin. When the filler content is increased to $65 \%$, the DRC exhibits enhanced mechanical properties. However, the refractive index of quartz is higher than that of the resin matrix. This mismatch induces light scattering and allows less light to penetrate the deep layer. In addition, the DRC is hard to polish and prone to wear.

\subsection{Ground Glass Micropowder}

Ground glass powder fillers, also known as alkaline glass fillers, have a smaller particle size $(0.6-10 \mu \mathrm{m})$ than that of ground quartz powder. Though $\mathrm{SiO}_{2}$ is the main component, glass powder also contains $\mathrm{Ba}, \mathrm{Sr}$, and other elements [29]. These elements render composites with $\mathrm{X}$-ray radiopacity without the need for additional radiopaque agents, which is beneficial for clinical diagnosis [16,30,31]. Some commercial DRCs, such as TetricEvoCeram (Ivoclar Vivadent, Schaan, Liechtenstein), Grandio (Voco, Cuxhaven, Germany), Esthet-x (Dentsply Caulk, Milford, DE, USA), and Herculite XRV (Kerr, Brea, CA, USA), contain this type of filler. Some DRCs have additional functionalities resulting from the addition of different types and concentrations of metallic elements to fillers [16], e.g., antibacterial silver [32]. In clinical application, when these DRCs are exposed to water or saliva in the oral environment, the metal ions may leach over time, inducing mixed effects on the DRC properties [33-37].

As DRCs tend to accumulate more bacterial biofilms and plaques, which is one of the main causes leading to restorative failure. Research has been carried out to specifically address secondary caries by developing novel DRCs with a biofilm-suppression ability and remineralization function for early caries recovery. Antimicrobial nanoparticles (e.g., $\mathrm{Ag}$ and $\mathrm{ZnO}$ ) have been used in combination with other micropowders in DRCs [38].

\subsection{Colloidal Silica Nanopowder}

Colloidal silica nano-powder was prepared using the nanotechnology referred to as the Stöber process [39,40]. This filler is much smaller (approximately $0.04-0.4 \mu \mathrm{m}$ ) than the abovementioned ground quartz micropowder and the ground glass micropowder. Most of these fillers are spheres with a lower surface roughness (Figure 2) [41], which improves the polishing property of DRCs. Nanosized $\mathrm{SiO}_{2}$ particles have been studied extensively and expanded to nanoclusters and mesoporous fillers. Due to the large specific surface area of nanosized $\mathrm{SiO}_{2}$ particles, the resin matrix viscosity dramatically increases and limits the content of nano- $\mathrm{SiO}_{2}$ in DRCs, leading to relatively poor mechanical properties if only one kind of this type of filler is used. In addition, nanosized $\mathrm{SiO}_{2}$ particles tend to agglomerate in the resin matrix because of their large specific surface area, thus forming stress concentrations in composites. Therefore, commercial DRCs filled with neat nanosized $\mathrm{SiO}_{2}$ particles are rare. Nanosized $\mathrm{SiO}_{2}$ particles have been extensively used in combination with other types of fillers (microparticles, fibrous fillers, whiskers, etc.), which can significantly improve the content of the filler, enhancing the mechanical properties [42-44] of DRCs and reducing polymerization shrinkage to a certain extent [24]. Alternatively, nanosized $\mathrm{SiO}_{2}$ particles can be used with other nanoparticles to form nanoclusters with reduced viscosity and enhance the properties of DRCs. They will be further discussed in Section 5.4.

\subsection{Hydroxyapatite (HA) Powder}

HA is an essential component of enamel and dentin. HA particles have low solubility at physiological $\mathrm{pH}$ [45]. When the $\mathrm{pH}$ is below 5.5, the dental hydroxyapatite undergoes dissolution, and some cariogenic bacteria are activated [46]. Hence, developing DRCs with remineralization capability will help reverse early caries. Nanoparticles of amorphous calcium phosphate, with a size of about $100 \mathrm{~nm}$, have been incorporated into DRCs to gain better ion-release profiles due to the small size and increased surface area for 
chemical interactions [47]. This novel nanocomposite not only released high levels of Ca and $\mathrm{P}$ ions at low $\mathrm{pH}$ for remineralization but also demonstrated superior mechanical properties. HA powders with high aspect ratios have also been investigated [48-53], e.g., whiskers and fibers, but the dispersion and interfacial adhesion with the resin matrix remain unsatisfactory. In recent research, urchin-like HA exhibited stronger interfacial adhesion and improved mechanical properties of the resin composite than other types of HA fillers [54]. This will be discussed in more detail in Section 5.

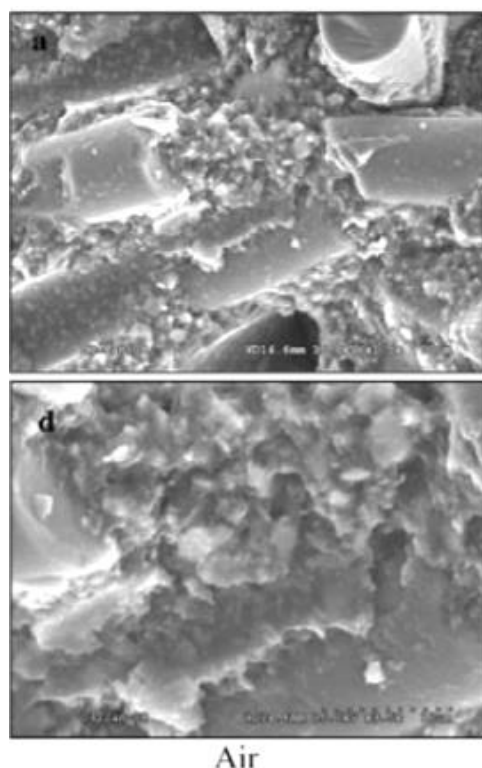

Air

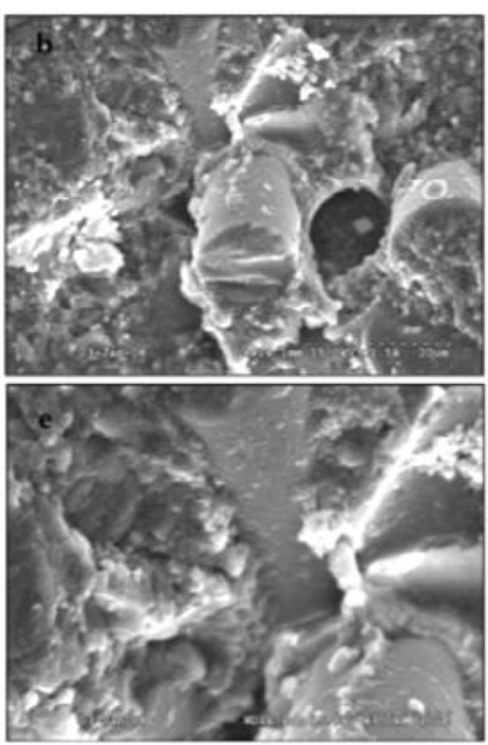

Water

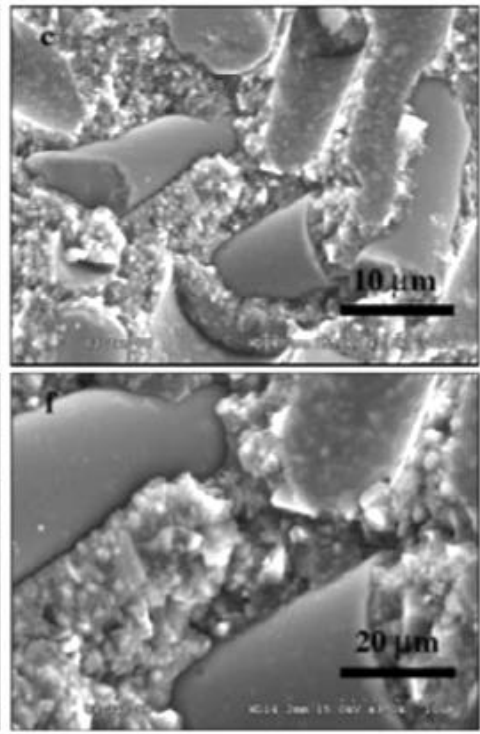

50/50 Ethanol/Water

Figure 2. SEM micrographs of the fracture surface of short-glass-fiber-reinforced resin composites aged for 6 months in three different media: (a,d) air; (b,e) distilled water; and a (c,f) 50:50 (v/v) mixture of ethanol and distilled water. The images indicate the relatively large sizes of the fiber fillers compared with the surrounding particle fillers and the separation of the fiber fillers from the resin matrix in ethanol/water $(\mathbf{c}, \mathbf{f})$ compared with the other media. Images from [41].

\subsection{Prepolymerized Powders}

A pre-polymerized particle filler is produced by a multi-step process: ultra-fine filler is added to the resin matrix with mechanical mixing, followed by thermal polymerization and subsequent polymer grinding. This filler can significantly reduce the viscosity of the resin matrix as the filler loading level increases. In this DRC, there is no requirement that the pre-polymerized resin is the same as the final resin matrix [55]. The resultant composite has the advantage of low polymerization shrinkage and water absorption [56]. However, the flexural strength and modulus of the DRC are lower than those of hybrid composites [57].

\section{Fibrous Fillers and Their Development}

Compared to other types of fillers, the chemical compositions of fibrous fillers are different and feature a higher aspect ratio [58]. In terms of composition and aspect ratio, fibrous fillers can be divided into microwhiskers, shortglass microfiber, ceramic nanofiber, polymer nanofiber, and nanotube (Table 2). Among them, polymer nanofiber has the lowest rigidity. The whisker filler has relatively high rigidity and a low aspect ratio. Nanotube has a hollow tubular microstructure. Polymer and ceramic nanofibers have been extensively studied. The mechanical properties of DRCs can be considerably improved by the inclusion of only small amounts of fibrous fillers [59-65], which can strengthen and toughen DRCs through pinning, fiber pulling out, crack deflection, and bridging mechanisms. Other factors that influence the mechanical properties of the final DRCs are the content and orientation of the fibrous filler as well as the interfacial bonding between the fibrous filler and the resin matrix $[62,66]$. Generally, fibrous fillers are not added in large quantities due to their tendency for severe agglomeration, observed in microsized silicon carbide and 
silicon nitride whiskers $[67,68]$, short glass fibers $[65,69,70]$, and nanosized polymer and ceramic fibers $[24,71]$.

Table 2. Characteristics of various fibrous fibers.

\begin{tabular}{ccc}
\hline Filler Types & Chemical Composition & Dimension \\
\hline Microwhisker & Silicon nitride & Diameter: $0.1-2 \mu \mathrm{m} ; \mathrm{mean}=0.4 \mu \mathrm{m}$ \\
& Silicon carbide & Length: $2-30 \mu \mathrm{m} ; \mathrm{mean}=5 \mu \mathrm{m}$ \\
& & Diameter: $0.1-3 \mu \mathrm{m} ; \mathrm{mean}=0.7 \mu \mathrm{m}$ \\
Length: $2-100 \mu \mathrm{m} ; \mathrm{mean}=14 \mu \mathrm{m}$
\end{tabular}

\subsection{Microwhisker}

A whisker is a kind of filament grown in the form of a single crystal under natural or artificial conditions. Compared with other fillers, a whisker is defect-free, e.g., it lacks grain boundaries, dislocations, and holes. Its extraordinary strength is close to that of the theoretical value for a single crystal. Xu et al. [68] studied silicon nitride and silicon carbide whiskers and found that the type of whisker and the ratio of whiskers to silica significantly influenced the mechanical properties of the DRCs. These whiskers appeared to be well bonded with the resin matrix at whisker-resin interfaces (Figure 3A,B). The inclusion of silicon nitride whiskers also improved the strength and toughness of DRCs more than silicon carbide whiskers. Silicon carbide whiskers were capable of improving modulus and hardness compared to silicon nitride whiskers. When the ratio of silicon nitride whiskers/silica was 1:1, the DRC achieved the highest strength, of $246 \pm 33 \mathrm{MPa}$; when the ratio of silicon carbide whiskers/silica was 5:1, the maximum strength of the DRC was $210 \pm 14 \mathrm{MPa}$. In addition, by fusing dicalcium phosphate nanoparticles to the silicon carbide whisker's surface (Figure 3C) [72], the final DRC released calcium and phosphorus ions and still maintained good mechanical performance with high flexural strength (167 MPa) [67].
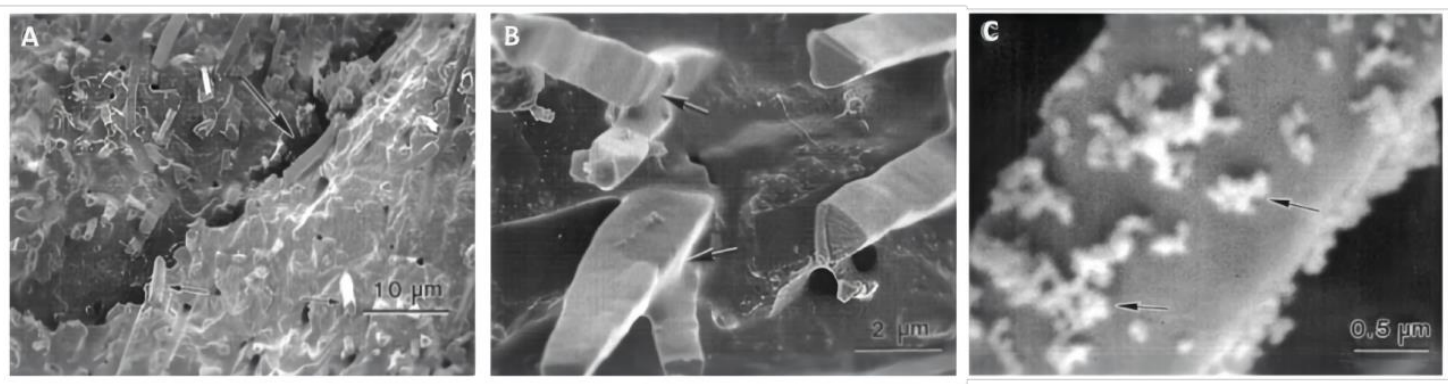

Figure 3. SEM micrographs of the fracture surfaces of the whisker composite at different ratios of whiskers to silica. (A) The composites containing silica-fused whiskers showed rougher fracture surfaces, with large fracture steps (large arrows) and pulled-out whiskers (small arrows). (B) The whiskers appeared to be well bonded with the matrix resin at whisker-resin interfaces, as indicated by the arrows. (C) The silica particles on the surface of the whiskers. Images from [68].

\subsection{Short Glass Microfiber}

Short glass fiber is close to silica in chemical composition and has been widely used in DRCs. Usually, these fibers are more translucent than silicon-carbide-whisker-reinforced DRCs. Such DRCs used in clinics include Ever X Posterior (GC Dental, Tokyo, Japan), Restolux (Lee Pharmaceutical, South El Monte, CA, USA), and NovaPro ${ }^{\circledR}$ Flow Flowable 
Composite (NovaPro, Mojave Court, CA, USA). They are usually used in high-load-bearing areas (especially in the posterior tooth fossa). Compared with DRCs with particulate fillers, short glass fibers have a better reinforcing effect in DRCs [73,74]. For example, compared with pure particulate resin composite Z250 (3M ESPE, St. Paul, MN, USA), Garoushi et al. [65] found that the inclusion of $22.5 \mathrm{wt} \%$ short glass fiber filler in the resin composite increased the flexural strength by nearly $99 \%$, the compressive strength by $85 \%$, and the fracture toughness by $300 \%$. According to that study, the factor contributing to the reinforcing and toughening effects of short E-glass fibers in the DRC is the interpenetratingpolymer-network-polymer matrix (IPN-polymer matrix) structure (Figure 2) [41], which could include crack deflection, bridging, pinning, and other fracture energy absorption mechanisms (Figure 4) [65].
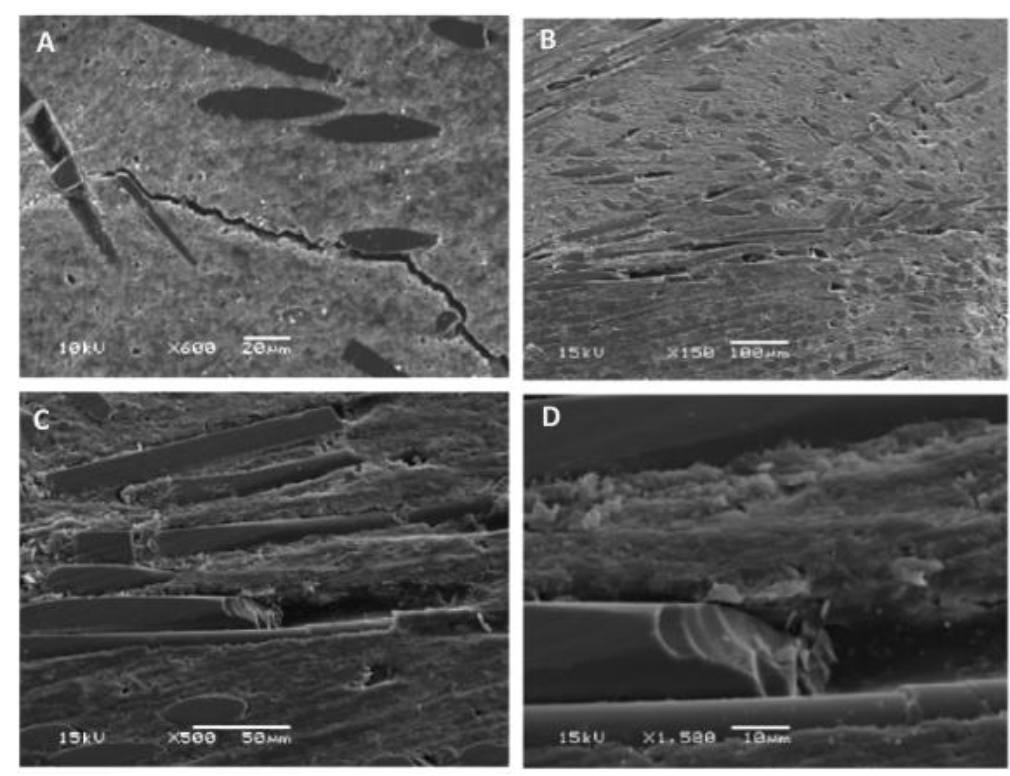

Figure 4. SEM micrographs of (A) a polished surface of a fiber composite with a propagating crack and (B-D) fracture surfaces with different magnifications showing fractured glass fibers Images from [65].

Lassila et al. [69] prepared a resin composite by mixing $27 \mathrm{wt} \%$ E-glass fiber (with micrometer- and millimeter-length scales) into $23 \mathrm{wt} \%$ dimethacrylate-based resin matrix and then adding $50 \mathrm{wt} \%$ silanized silica particulate filler. Compared with the conventional posterior DRC Filtek Supreme (3M ESPE, St. Paul, MN, USA), the fracture toughness and the flexural strength of this composite increased from 1.2 to $4.7 \mathrm{MPa} \cdot \mathrm{m}^{1 / 2}$ and from 103.5 to $155 \mathrm{MPa}$, respectively. This again demonstrates that glass fiber has better reinforcing and toughening effects in a resin composite. However, the challenges of using glass fiber are water absorption and the leaching of soluble inorganic oxides, which aggravate the reduction in mechanical properties of glass-fiber-reinforced DRCs used in the oral environment.

\subsection{Ceramic Nanofibers}

Compared to microsized shortglass fibers, nanosized ceramic fibers $\left(\mathrm{SiO}_{2}\right.$, zirconiayttria (ZY), and zirconia-yttria-silica (ZYS)) have a better reinforcing effect on DRCs when used in conjunction with other particulate fillers [24,75]. Particles were well dispersed in the interpenetrating polymer network (IPN) structure with nanofibers, as shown in Figure 5 [24]. Even a small amount of ceramic nanofibers was able to significantly improve the flexural strength, elastic modulus, and work of fracture of DRCs. In a study by Gao et al. [76], the flexural strength, elastic modulus, and work of fracture values of nanoglass-fiber-filled composites were increased by as much as $44 \%, 29 \%$, and $66 \%$, respectively. In another study [24], where the content of $\mathrm{SiO}_{2}$ nanofibers was $5 \mathrm{wt} \%$, the flexural strength of the final DRC reached $118 \mathrm{MPa}$. Compared to $\mathrm{SiO}_{2}$ nanoparticles, 
zirconia-silica (ZS) and ZYS ceramic nanofibers showed better performance in improving the overall properties of DRCs, especially with improved wear resistance and reduced polymerization shrinkage [75]. The mechanical properties of DRCs with different contents of ZS or ZYS ceramic nanofibers were compared. When the DRCs contained $70 \mathrm{wt} \%$ glass particle fillers and $2.5 \mathrm{wt} \% \mathrm{ZS}$ nanofibers or $5.0 \mathrm{wt} \% \mathrm{ZYS}$ nanofibers, the DRCs exhibited the best performance in terms of flexural strength (FS), flexural modulus (FM), and energy at break (EAB). Nevertheless, the strengthening effect decreased when the content of ZS ceramic nanofibers was increased to $7.5 \mathrm{wt} \%$, due to aggregation. This might be attributed to the stress concentration zone induced by nanofiber aggregates, leading to a weakened resin composite [77].
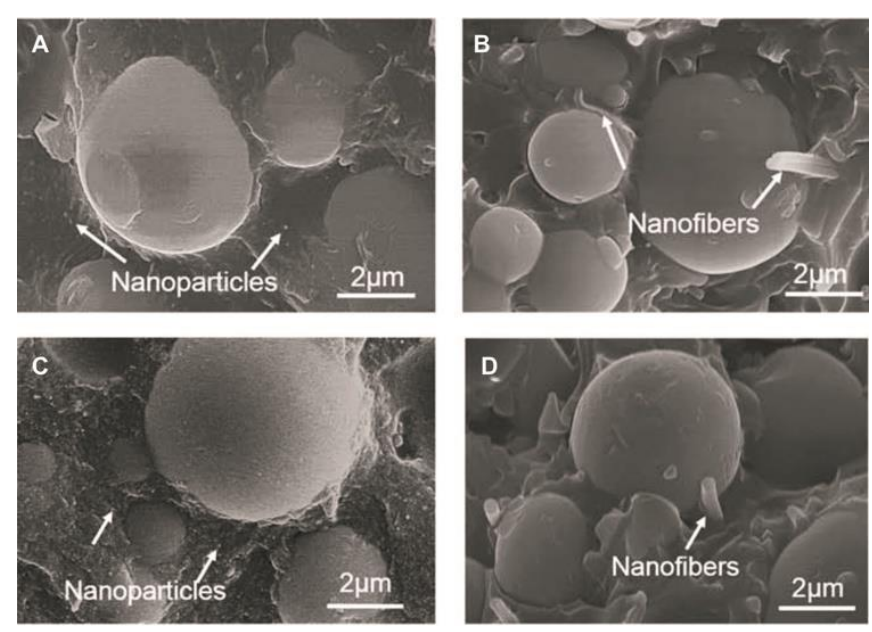

Figure 5. SEM micrographs of fractured surfaces of the Bis-GMA/TEGDMA composite reinforced with (A) $5 \mathrm{wt} \% \mathrm{SiO}_{2}$ nanoparticles and $60 \mathrm{wt} \%$ microparticles;(B) $5 \mathrm{wt} \% \mathrm{SiO}_{2}$ nanofibers and $60 \mathrm{wt} \%$ microparticles;(C) $10 \mathrm{wt} \% \mathrm{SiO}_{2}$ nanoparticles and $60 \mathrm{wt} \%$ microparticles; and (D) $10 \mathrm{wt} \% \mathrm{SiO}_{2}$ nanofibers and $60 \mathrm{wt} \%$ microparticles. Images from [24].

\subsection{Polymer Nanofibers}

Polymer nanofibers are usually used in engineering composites. Fong et al. studied DRCs reinforced with polymeric fibers [78]. Nylon-6 nanofibers were used and showed apparent reinforcement and toughening effects. When the content of polymer nanofibers was $5 \mathrm{wt} \%$, the flexural strength and fracture toughness of the resin composite was $36 \%$ and $42 \%$ higher, respectively, than those of pure resin. However, the bonding interface between nylon- 6 and the matrix required further optimization [24]. The hydrophilicity of nylon polymer induced water absorption, which reduced the strength of the nylon nanofiber itself as well as that of the composite.

\subsection{Nanotubes}

Nanotubes are hollow fibrous fillers with a high aspect ratio. They have the same strengthening and toughening mechanisms as fibrous fillers. Nanotubes vary in chemical composition, with the most widely studied being carbon nanotubes [79]. According to Zhang et al., silanized methacrylic groups on the surface of carbon nanotubes improved the flexural strength of the resin composite by $23 \%$, from 115 to $142 \mathrm{MPa}$, albeit its appearance was un-aesthetically dark [80]. In two other separate studies, electrospunnylon$6 /$ multilayer carbon nanotubes [81] and kaolinite nanotubes [82] were also used as reinforcements for the resin composite. However, the reinforcing effect of nanotubes in composites was strongly dependent on the content of nanotubes. When the loading of nanotubes exceeded $5 \%$, the strengthening effect diminished. In another study on triclosanencapsulated halloysite nanotubes (HNT/TCN), Cunha [83] found that the addition of $8 \mathrm{wt} \% \mathrm{HNT} / \mathrm{TCN}$ had a significant effect on the flexural strength of the composite, but the polymerization stress was higher than that of the composite without HNT, which might 
be connected with nanotube loading. When the mass fraction was increased to more than $10 \mathrm{wt} \%$, the weakening instead of reinforcing effect was dominant.

\section{Novel-Shaped Fillers and Their Development}

Novel-shaped fillers include porous and mesoporous particles, urchin-like particles, nanoclusters, tetrapod-shaped whiskers, core-sheath fibers, flakes, and microcapsules (Table 3). Despite some being derived from pre-existing particulate and fibrous fillers, the morphology (e.g., urchin or tetrapod shape) and composition (dissimilar core-sheath materials) of novel-shaped fillers are beyond the boundaries of those for traditional fillers. Their surface either provides more mechanical chimerism (e.g., open-pore penetration or anchorage) or enhances the interfacial bonding (e.g., through more adhesive sheath).

Table 3. Types of novel-shaped fillers by morphology modification.

\begin{tabular}{|c|c|c|c|}
\hline Filler Types & Chemical Composition & Shape & Size \\
\hline Porous particle & Glass-ceramic & Particle-like & $2-4 \mu \mathrm{m}$ \\
\hline Mesoporous particle & Silica & N.I. ${ }^{a}$ & Average $496 \mathrm{~nm}$ \\
\hline UHA particle & Hydroxyapatite & Sea urchin & $2-3 \mu \mathrm{m}$ \\
\hline Nanocluster particle & $\mathrm{SiO}_{2}, \mathrm{ZrO}_{2}$ & Particlelike & $0.07-2.7 \mu \mathrm{m}$ \\
\hline $\mathrm{T}-\mathrm{ZnO}$ whisker & $\mathrm{ZnO}$ & Tetra-needle & $0.18-0.21 \mu \mathrm{m}$ \\
\hline Core-sheath fiber & $\begin{array}{c}\text { Zirconia/Silica, } \\
\text { PAN-PMMA, } \\
\text { T-ZnOw/PANI }\end{array}$ & Fibrous & $\begin{array}{c}\text { Diameter: } 220-300 \mathrm{~nm} \\
\text { Diameter: } 300-400 \mathrm{~nm} \\
\text { N.I. }\end{array}$ \\
\hline Glass flake & $\mathrm{SiO}_{2}, \mathrm{Al}_{2} \mathrm{O}_{3}, \mathrm{CaO}$, et al. & Flakes & Diameter: $15-160 \mu \mathrm{m}$ \\
\hline Microcapsule & $\begin{array}{c}\text { Polymer shell with healing } \\
\text { liquid inside }\end{array}$ & Capsules & Diameter: 10-300 $\mu \mathrm{m}$ \\
\hline
\end{tabular}

a N.I. = Not informed.

\subsection{Porous Particles}

Depending on the pore size and shape, porosity, and chemical composition of the particles, porous particulate fillers can improve mechanical performance and drug-releasing $[84,85]$. The typical morphology of a porous filler is shown in Figure 6 [86].
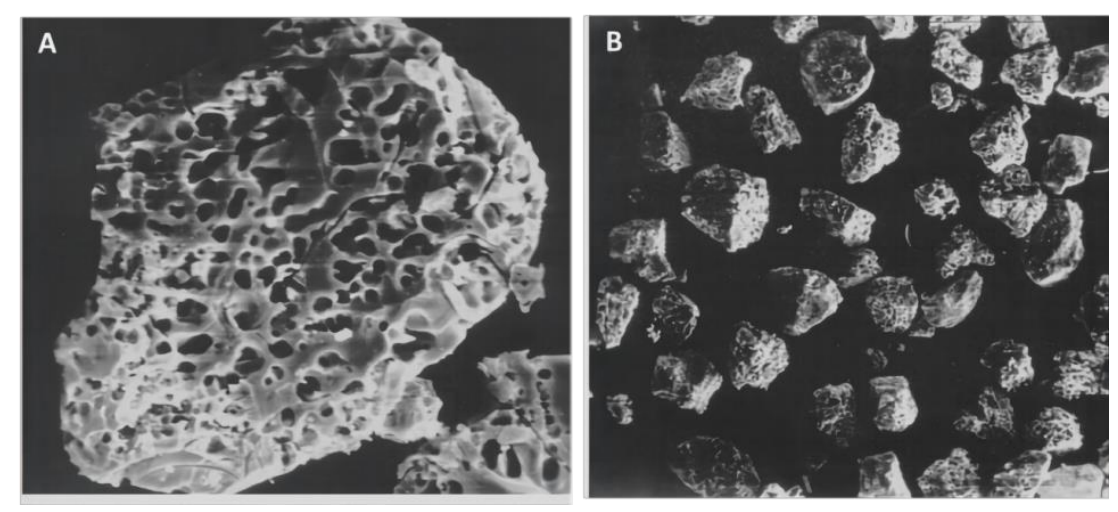

Figure 6. SEM micrographs of porous fillers after HF acid etching were shown at magnifications of (A) $2000 \times$ and (B) $500 \times$. The liquid resin can enter the pores of the porous fillers, and the resulting strength effects are related to this phenomenon. Images from [86].

Compared with traditional dense fillers, porous fillers can be penetrated by liquid resin, which can enhance the bonding strength between filler and resin matrix after crosslinking, thereby improving the mechanical properties of DRCs. In addition, the strong bonding between the porous filler and the resin matrix prevents the filler and the resin matrix from detaching, which can improve the wear resistance of DRCs [87]. Zandinejad et al. and Liu et al. [86,88] confirmed that adding porous glass-ceramic powder fillers improved the flexural strength and modulus of the DRCs but had less effect on 
tensile strength. However, the flexural strength did not change proportionally with the increasing porosity of the filler particles [88]. Porosity itself was not a determining factor in the mechanical strength of DRCs. The degree of resin penetration into the pores of porous fillers was another factor to be considered. If the resin matrix was incompletely infiltrated, the micromechanical coupling between porous fillers and the resin matrix was weak, which resulted in lower mechanical properties, especially flexural strength. A study by Ruddel et al. [61] validated this hypothesis. Two methods were investigated to address the resin infiltration problem. The first involved mixing porous fillers and resin under vacuum [89], and the second to add solvents to reduce resin viscosity and facilitate infiltration [90]. A novel DRC was proposed based on microfillers of anodic nanoporous alumina. This material exhibited better mechanical properties but seemed prone to aging, and the mechanical properties weakened dramatically when the DRC was loaded with drugs [85].

\subsection{Mesoporous Silica Particles}

To control filler pore size and uniformity, mesoporous silica particles may be a better option. Wang et al. [91] introduced a novel porous filler, termed wrinkled mesoporous silica (WMS), which had a monodisperse spherical core with wrinkles extending radially outward from the center. Its rugged structure is shown in Figure 7 [91]. Similar to a porous filler, mechanical interlocking between resin matrix and WMS strengthened the DRC, improving its flexural strength, flexural modulus, compressive strength, and Vickers microhardness, compared to normal silica particles with the same diameter.
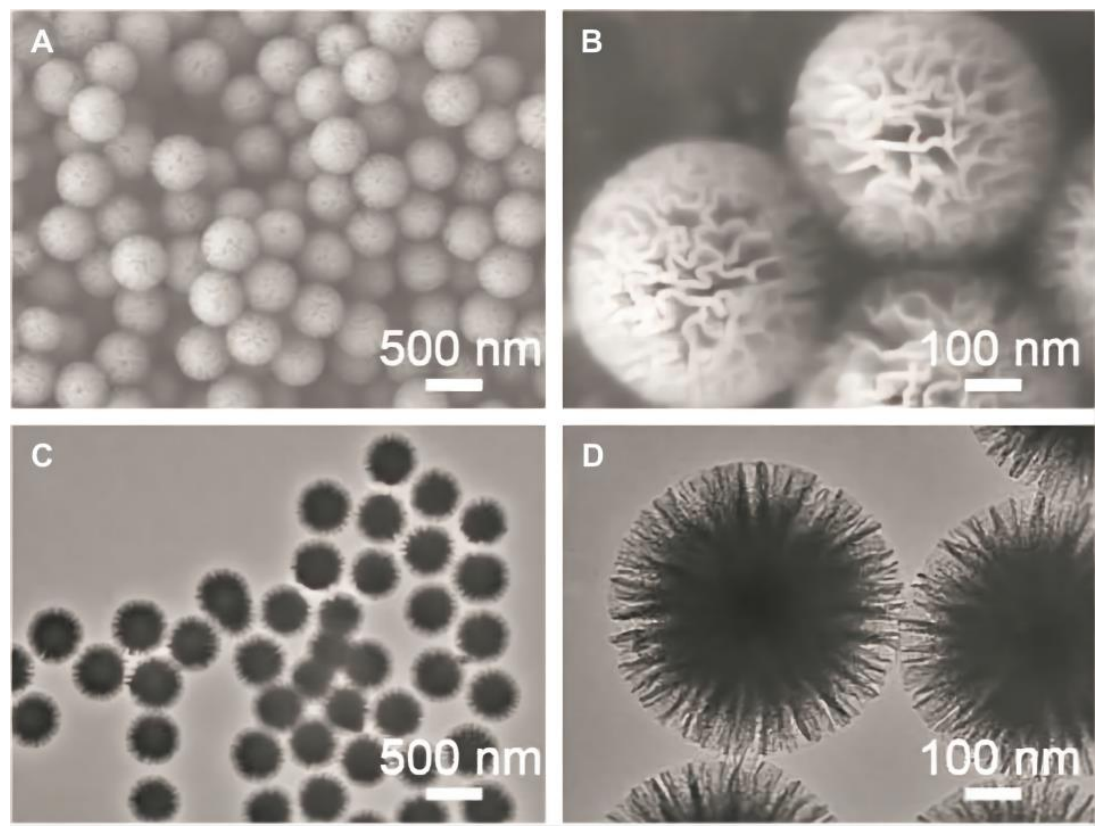

Figure 7. (A,B) Field emission scanning electron microscopy (FE-SEM) micrographs of wrinkled mesoporous silica and (C,D) TEM images of different magnifications of wrinkled mesoporous silica.Images from [91].

\subsection{Urchin-like Fillers}

In previous studies, HA whiskers or nanofibers were fabricated to improve the mechanical properties of DRCs [48,51]. Recently, a new type of urchin-like HA (UHA) powder combining the characteristics of both whiskers and fibers has emerged. This type of filler can be tightly embedded in the resin matrix, increasing the interfacial area and the bonding strength between the fillers and the matrix. In a study by Liu et al. [54], the enhancement effect of UHA was found to be better than that of irregular particle hydroxyapatite (IPHA) or hydroxyapatite whisker (HAW)-reinforced DRCs. It was found that with the increase in UHA content (20 and $30 \mathrm{wt} \%$ ), the flexural modulus and microhardness of DRCs in- 
creased, but not strength. This might be attributed to the silanized UHA fillers being closely embedded in the matrix to form a strong cohesion between the resin matrix and fillers. The shape of the sea urchin might reduce aggregation in the resin matrix compared to IPHA and HAW fillers. The UHA particles were closely intertwined and did not affect the resin monomer movement, which improved resistance to breakage even under a high load. Integration of silanized UHA into DRCs containing silica nanoparticles could further improve the strength and modulus of DRCs. Figure 8 shows SEM images of UHA fillers (A) and $20 \mathrm{wt} \%$ UHA reinforced composite (B). Figure $8 \mathrm{~B}$ shows a desirable bonding between UHA fillers and the matrix. No appreciable gaps or voids appeared on the fracture surface. In addition, UHA with an urchin-like structure was fully integrated into the resin matrix, forming strong interfacial bonding, which made the stress transfer more efficient between the UHA and the matrix.
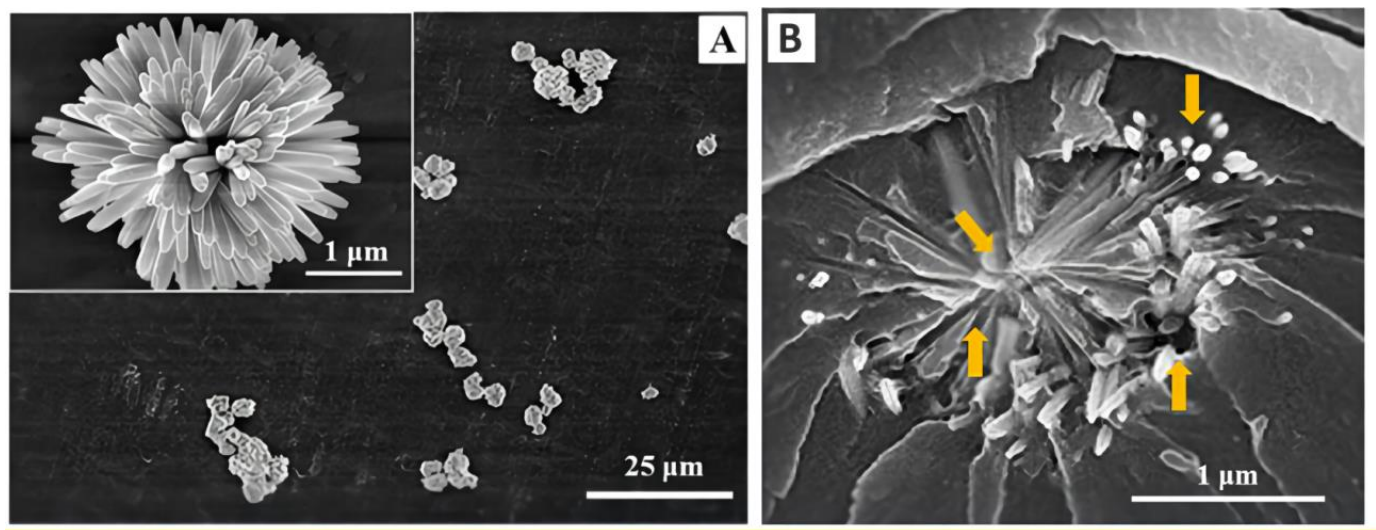

Figure 8. SEM micrographs of (A) UHA fillers and (B) the fracture surface of the dental resin with $20 \mathrm{wt} \%$ UHA. Images from [53].

\subsection{Nanocluster Fillers}

Nanoclusters are secondary particles created through the dense fusion of nanoparticles, typically $\mathrm{SiO}_{2}$ or $\mathrm{ZrO}_{2}$ or hybrid particles [92]. Several particles are fused together to form a large, covalently bonded cluster [93]. The silane coupling agent can penetrate gaps of the nanoclusters, improving the mechanical strength of the DRC [94,95].

Randolph et al. [17] revealed that Filtek Supreme XTE (3M ESPE, St. Paul, MN, USA) with nanoclusters exhibited better fracture strength than other commercial DRCs without nanoclusters. Nanoclusters in DRCs can absorb stress that promotes crack growth and, thus, fracture strength is improved. Novel bimodal $\mathrm{SiO}_{2}$ nanoclusters (as shown in Figure 9) were synthesized. The silica nanoclusters, namely, large, agglomerated particles consisting of numerous silica nanoparticles and silica aggregations with cavities, have a size distribution within the range of $0.07-2.70 \mu \mathrm{m}$ and are shown in Figure 9 [96]. When the DRCs contained $70 \mathrm{wt} \%$ filler ( $50 \mathrm{wt} \%$ bimodal $\mathrm{SiO}_{2}$ nanocluster and $20 \mathrm{wt} \%$ unimodal $\mathrm{SiO}_{2}$ ), the flexural strength $(104.8 \pm 4.4 \mathrm{MPa})$, flexural modulus $(6.2 \pm 0.3 \mathrm{GPa})$, and compressive strength $(205.8 \pm 14.3 \mathrm{MPa})$ of the DRCs were $28 \%, 48 \%$, and $42 \%$ higher, respectively, than those of the unimodal $\mathrm{SiO}_{2}\left(60 \mathrm{wt} \%\right.$ ) filled DRCs without bimodal $\mathrm{SiO}_{2}$ nanoclusters.

\subsection{Tetrapod-like Whiskers}

Like UHA fillers, the tetrapod-like $\mathrm{ZnO}$ whiskers(T-ZnOw) possess the same perfect surface as the traditional whiskers. Unlike traditional whiskers, $\mathrm{T}-\mathrm{ZnOw}$ shows a unique three-dimensional structure with four needles growing from one point, with the angle between two needles being 109.28 ${ }^{\circ}$ [97]. As shown in Figure 10, [20] this special structure provides $\mathrm{T}-\mathrm{ZnOw}$-filled DRCs with is tropic rather than anisotropic properties, meaning forces can be more evenly distributed inside the T-ZnOw-filled DRCs. The fillers' needles can create a more powerful interface through increased integration with the resin matrix. 

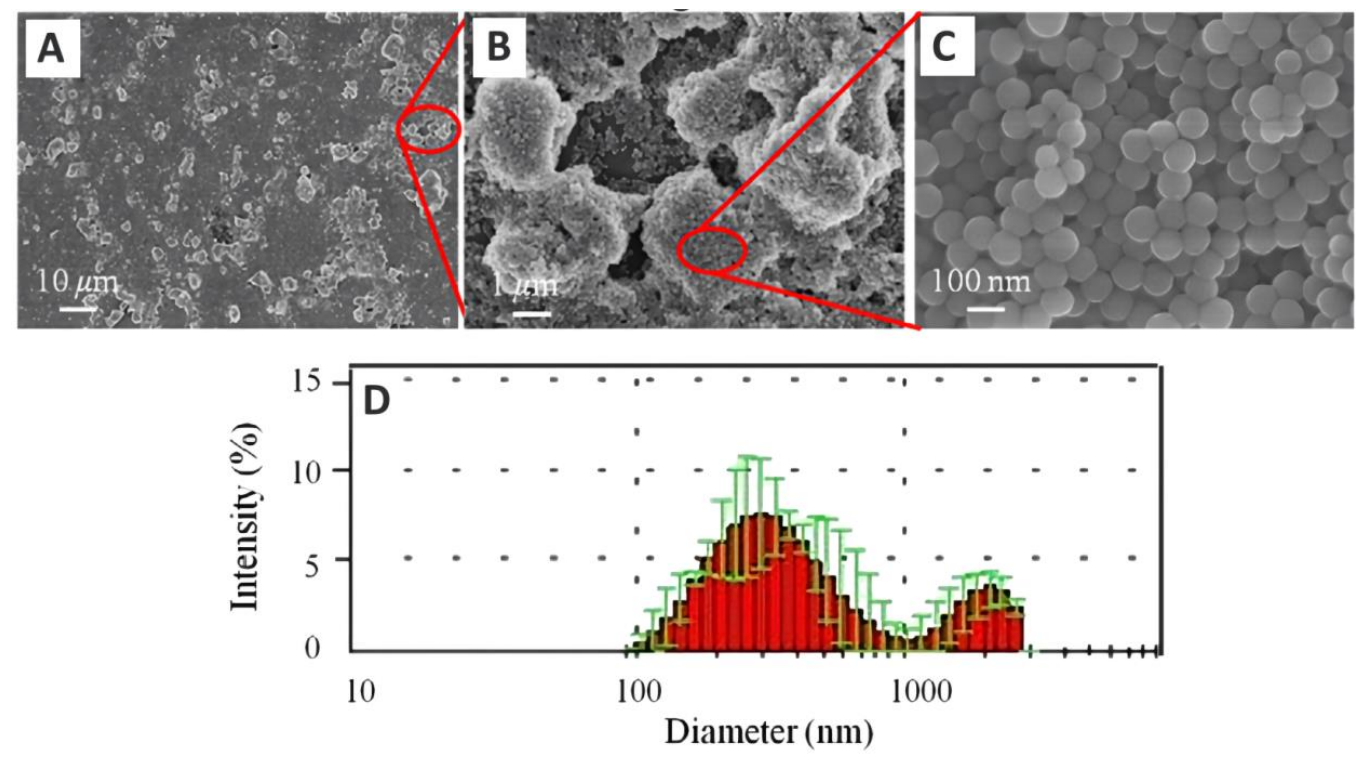

Figure 9. FE-SEM micrographs and particle size distributions of silica bimodal nanoclusters and magnified to varying degrees, indicated with scale bars of $10 \mu \mathrm{m}(\mathbf{A}), 1 \mu \mathrm{m}(\mathbf{B})$ and $100 \mathrm{~nm}(\mathbf{C})$ at selected regions, and their size distribution (D), respectively.Images from [96].
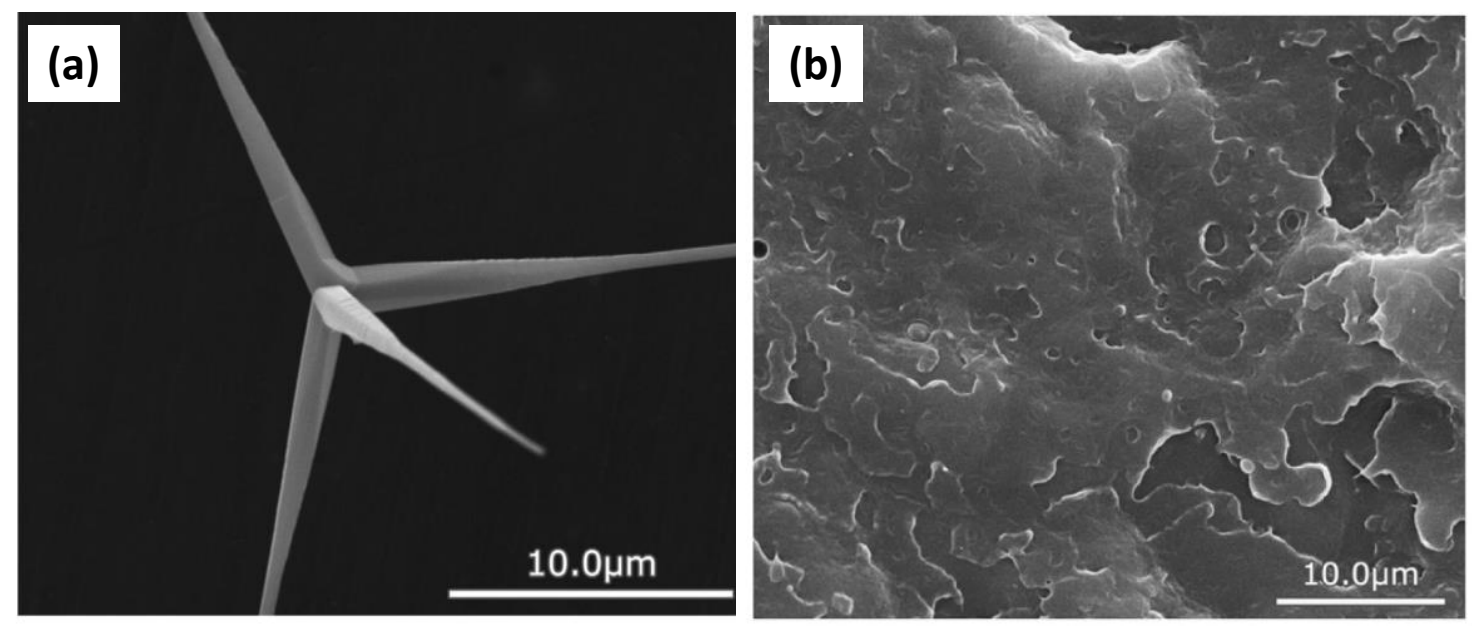

Figure 10. Typical SEM microphotograph of (a) a T-ZnOw whisker and (b) impact-fractured surfaces of composites with untreated T-ZnOw. Images from [20].

A study on tensile strength showed that $\mathrm{T}-\mathrm{ZnOw}$-reinforced DRCs could reach 26.5 MPa even if the T-ZnOw fillers were not treated with a coupling agent. The storage modulus was improved by adding T-ZnOw fillers. Moreover, the surface treatment of T-ZnOw fillers resulted in their becoming flexible. Either a silane coupling agent or a titanate coupling agent could improve the reinforcing effect of T-ZnOw fillers on the final composites. Though silane coupling agent treatment resulted in improved tensile strength, while titanate coupling agent treatment improved the impact strength [21], microcracks were formed at the interface between fillers and the resin matrix during the crosslinking process, leading to a change in the fracture mode of DRCs. This phenomenon was pronounced when the filler content was more than $10 \mathrm{wt} \%$.

\subsection{Core-Sheath Fillers}

In a study by Chen et al., a core-sheath structured T-ZnOw/polyaniline (PANI) composite filler was developed via graft polymerization [22]. As shown in Figure 11, PANI underwent in situ polymerization, which changed the surface wetting properties of T- 
ZnOw from hydrophilic to hydrophobic and, thus, facilitates interaction with the dental resin matrix; $\gamma$-aminopropyltriethoxysilane (APTS) played an essential role in ensuring a strong bonding and inducing in situ polymerization on the filler's surface. At the same time, the core-sheath structured T-ZnOw/PANIhad an increased surface area and interfacial bonding, which endowed the composites with better performance.
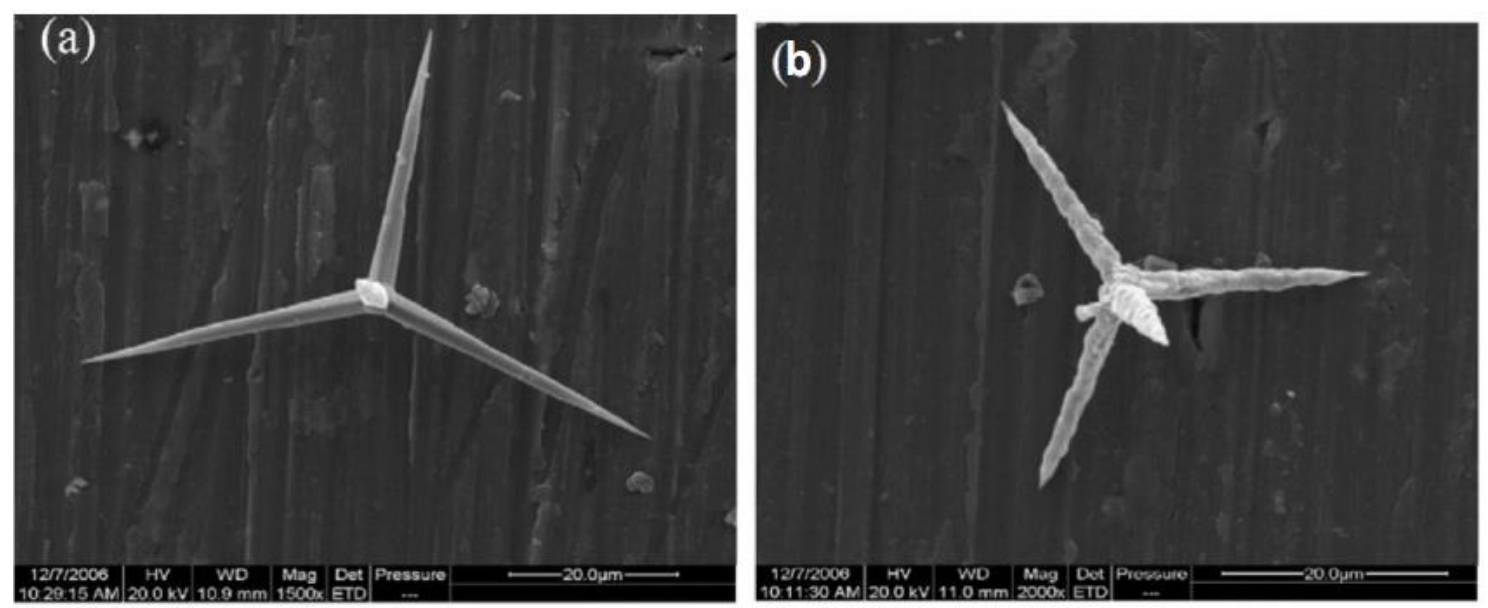

Figure 11. SEM micrographs of (a) an original T-ZnOw and (b) aT-ZnOw/PANI core-sheath structure. Images from [22].

Similarly, by examining the microstructure of the polymer-fiber-reinforced resin composite, Deng et al. [24] found that the bonding between polymer fibers and the resin matrix was not perfect. To improve the surface wetting and interfacial bonding strength, an electrospinning technique was used to fabricate core-sheath polymer nanofibers with polyacrylonitrile (PAN) as a core and poly (methyl methacrylate) (PMMA) as a sheath (Figure 12) [23]. Compared with pure resin, the flexural strength, elastic Young's modulus, and fracture work of composites reinforced with $7.5 \mathrm{wt} \%$ PAN-PMMA nanofibers increased by $18.7 \%, 14.1 \%$, and $64.8 \%$, respectively. In addition, the PAN-PMMA nanofibers had a drug-eluting capability.
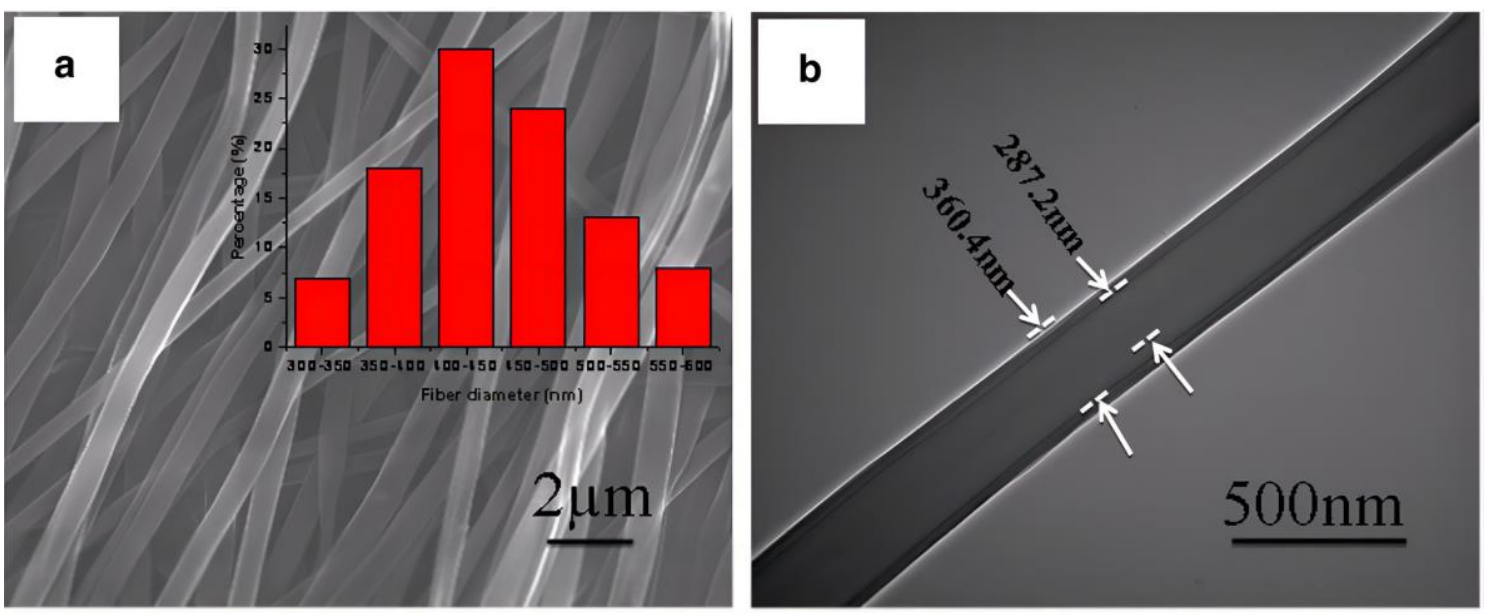

Figure 12. (a) SEM- and (b)TEM-micrographs of PAN-PMMA core-shell nanofibers. Images from [23].

Likewise, Li et al. [98] prepared ceramic nanofibers with yttria-stabilized zirconia as a core and silica as a sheath (i.e., ZY@S nanofiber) via a reactive coaxial electrospinning process (Figure 13). Compared to the ZY fiber, the ZY@S nanofiber combined the strong and tough $\mathrm{ZY}$ ceramic nanofibers with a silica sheath, which enabled improved interfacial bonding via silanization, as used for glass fibers. Compared with the unloaded resin, the 
flexural strength of the resin composite filled with $2.5 \mathrm{wt} \% \mathrm{ZY} @ \mathrm{~S}$ ceramic nanofibers was significantly improved $(45 \%)$.
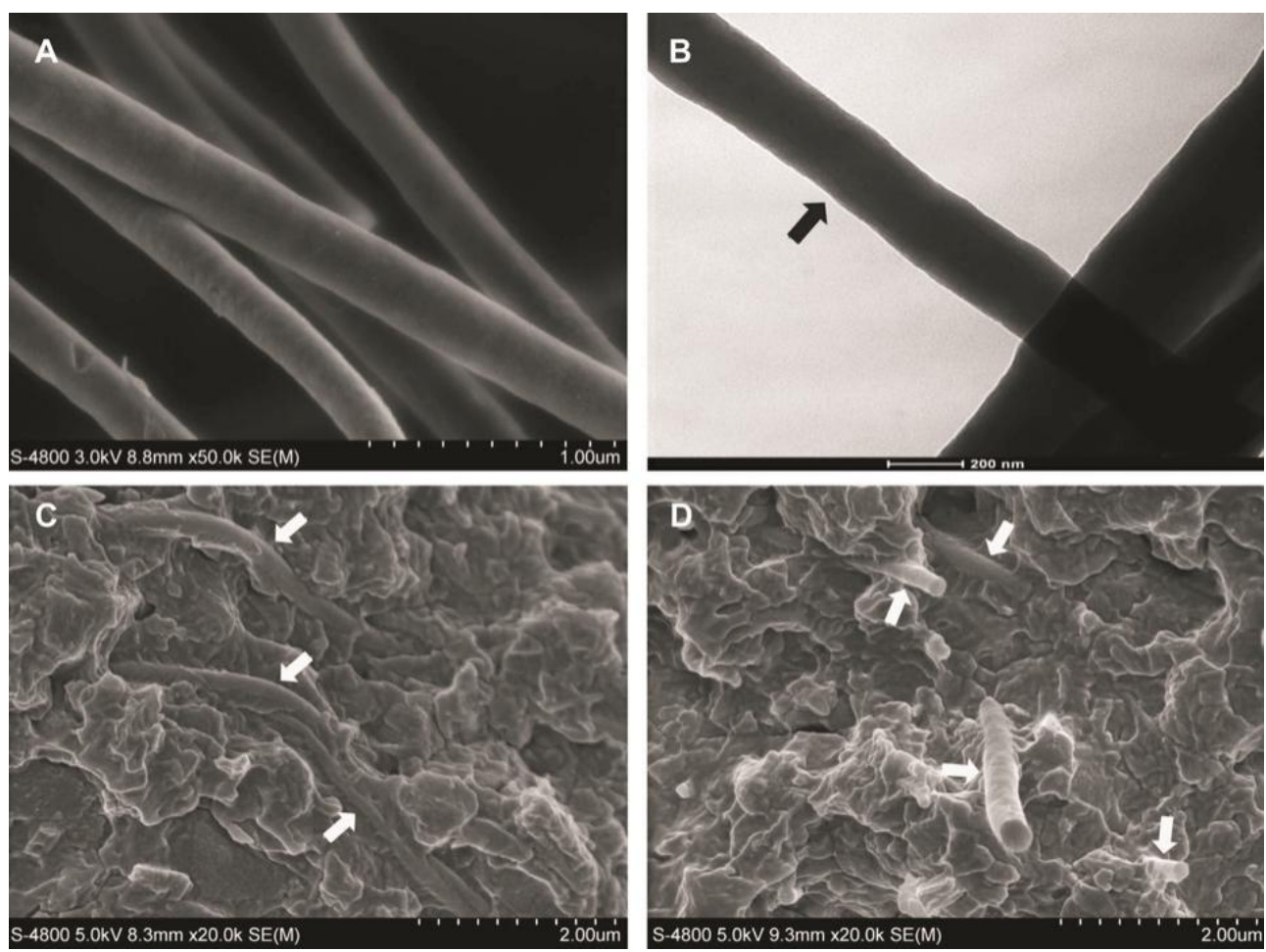

Figure 13. Morphology of electrospun ZY@S nanofibers: (A) SEM image (fiber diameter: $260 \pm 39 \mathrm{~nm}$ ) and (B) TEM image showing the core-sheath structure. Morphology of the composite fracture surface with (C) $2.5 \mathrm{wt} \% \mathrm{ZY} @ \mathrm{~S}$ nanofibers and (D) $5.0 \mathrm{wt} \% \mathrm{ZY} @ S$ nanofibers.Images from [98].

\subsection{Glass Flakes}

Glass flakes are generally modified $C$ glass fillers with a high aspect ratio. Commercial glass flakes are available in thickness ranging from $100 \mathrm{~nm}$ to $7 \mu \mathrm{m}$, with the d50 (median particle size) diameter ranging from 15 to $110 \mu \mathrm{m}$, and are categorized into three nominal diameter distributions (unmilled, milled, and micronized). Glass flakes with excellent inherent strength and high surface area are fundamental in providing dimensional and thermal stability to DRCs [99].

Glass flakes can be used alone or as a reinforced filler with silica particles in the resin matrix for improving the mechanical properties of DRCs. Significant improvement in the hardness and compressive strength was reported by Motohiro et al. for glass-flakereinforced DRCs. The improvement in the mechanical properties was dependent on the glass flake content and surface salinization conditions [100]. Glass flakes have also been shown to enhance the mechanical properties of silica-particle-filled DRCs, with $\gamma$-MPS salinization [101].

Compared with other fillers, glass flakes have the additional advantage of improving the aesthetic property of DRCs. In a study by Motohiro et al., a glass-flake-filled composite resin showed better translucency compared to its irregularly shaped counterpart. This was attributed to the large particle size and flat surface of the glass flake, which suppressed light scattering (Figure 14) [100]. Though an increasing haze was presented with the addition of microglass flakes (MGFs), MGFs with a smaller aspect ratio showed a significantly lower haze compared to irregular glass particles. Moreover, refractive indices (RIs) of such composites could be adjusted by the addition of different amounts of softener. As a result, the residual haze could be as low as $2 \%$, indicating high transparency [102]. 

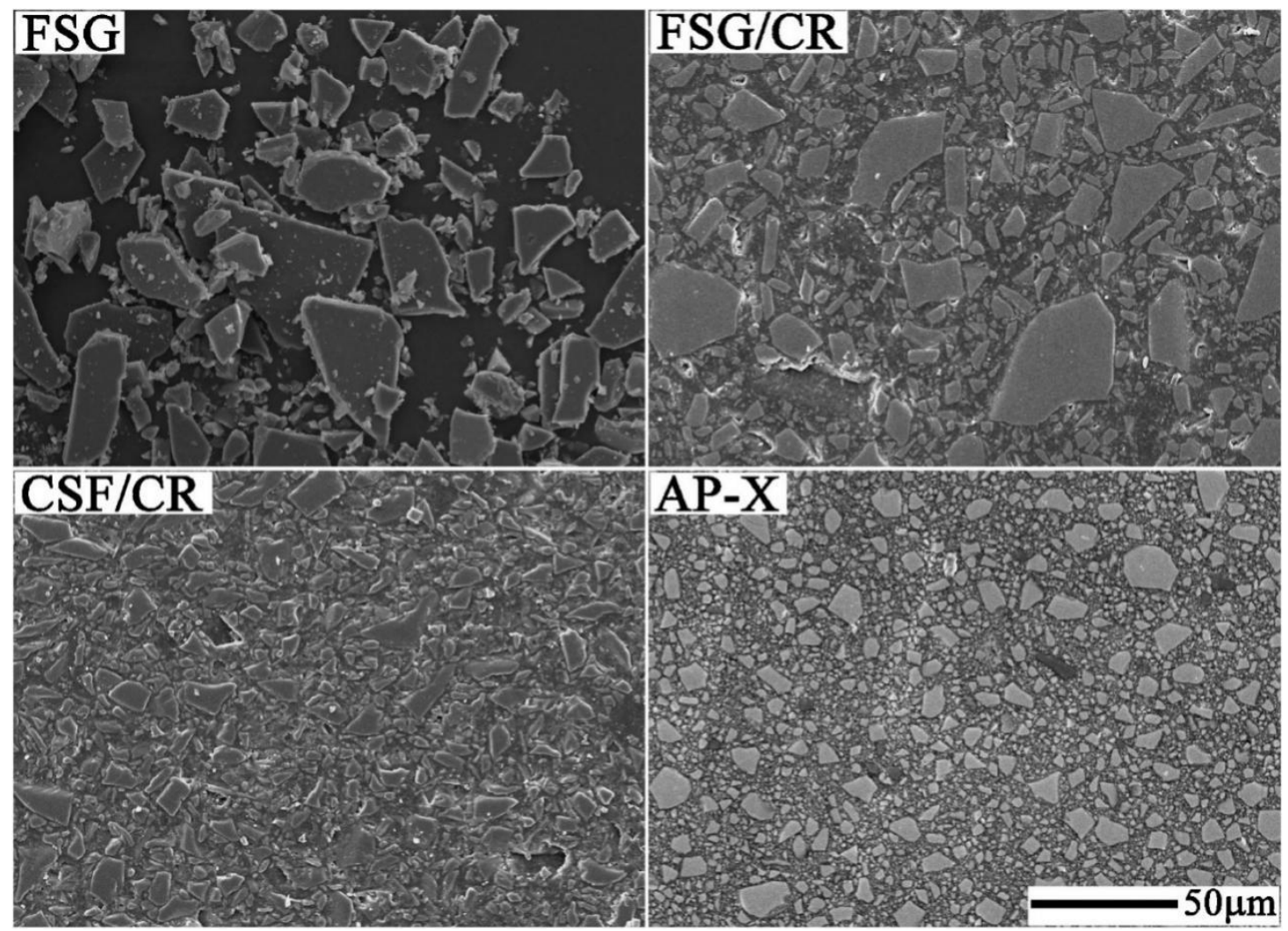

Figure 14. SEM images of flake-shaped glass (FSG), FSG/composite resin (CR) (60 wt \%), crushed silica filler (CSF)/CR $(60 \mathrm{wt} \%)$, and a commercial CR clearfil-AP-X. The FSG is platelet-shaped with a flat surface and is smaller than $50 \mu \mathrm{m}$. The particle size of FSG is larger than that of the CSF and the filler contained in AP-X. Images from [100].

With the concept of biomimetics, structural biological composites such as nacre (the protective inner layer of mollusk shells) offer much inspiration for the fabrication of composites with both superior mechanical properties and optical characteristics. Amini et al. combined glass flakes and poly (methyl methacrylate) (PMMA) using a centrifuge-based fabrication method that aligned and compacted the flakes into layers. This nacreous composite showed a four-fold increase in fracture toughness and a three-fold increase in flexural strength compared to conventional structural glasses. Additionally, by matching the refractive indices of the PMMA, a 73\% average optical transmittance was achieved [103]. This novel feature has potential for application in DRC improvement.

\subsection{Microcapsules}

Microencapsulation is a novel approach developed for endowing DRCs with selfhealing properties [104]. A microcapsule is a spherical particle with a polymer or glass shell that encloses healing liquid. When microcapsules are embedded into the resin matrix, they can rupture to release the healing liquid, which could flow into the cracked area and be exposed to a catalyst in the matrix and trigger polymerization to heal the crack $[105,106]$.

Then et al. [107] and Wertzberger et al. [108] studied two traditional self-healing systems, urea-melamine-formaldehyde (UMF) encapsulated dicyclopentadiene (DCPD) (no catalyst) and DCPD microcapsules with Grubb's catalyst, respectively. Their results showed that incorporation of a small number of microcapsules did not affect the performance of the resin matrix while the latter reported that $57 \%$ recovery of the original $\mathrm{K}_{\mathrm{IC}}$ was achieved despite being substantially filled (55 wt\%) with microcapsules.

Considering the potential toxicity and ease of fracture when mixed with fillers of polyurethane microcapsules, novel self-healing dental composites (SHDCs) have been developed with the use of glass ionomer cement (GIC) and silicate microcapsules. They 
have two additional components: (1) a healing powder (HP), i.e., strontiumfluoroaluminosilicate particles, and (2) a healing liquid (HL), i.e., aqueous solutions of polyacrylic acids encapsulated in silica microcapsules $[109,110]$. Huyang et al. reported that the average healing efficiency reached up to $25 \%$ when $10 \mathrm{wt} \%$ microcapsules were added with a slightly reduced elastic modulus in SHDCs. [110] The morphological and chemical observations confirmed the healing procedure as fracture, deliver, and heal (Figure 15) [111]. Yahyazadehfar et al. tested the same self-healing system with different silane coupling agents under cyclic loading and showed that methacrylate silane (MA-silanized) SHDCs achieved the best balance of healing efficiency $(24.2 \% \pm 3.8 \%)$ and fracture toughness at $5 \mathrm{wt} \%$ microcapsule loadings. Moreover, a significant increase in the resistance to fatigue crack growth with an increase of $580 \%$ in the fatigue life was observed in this new material [109].
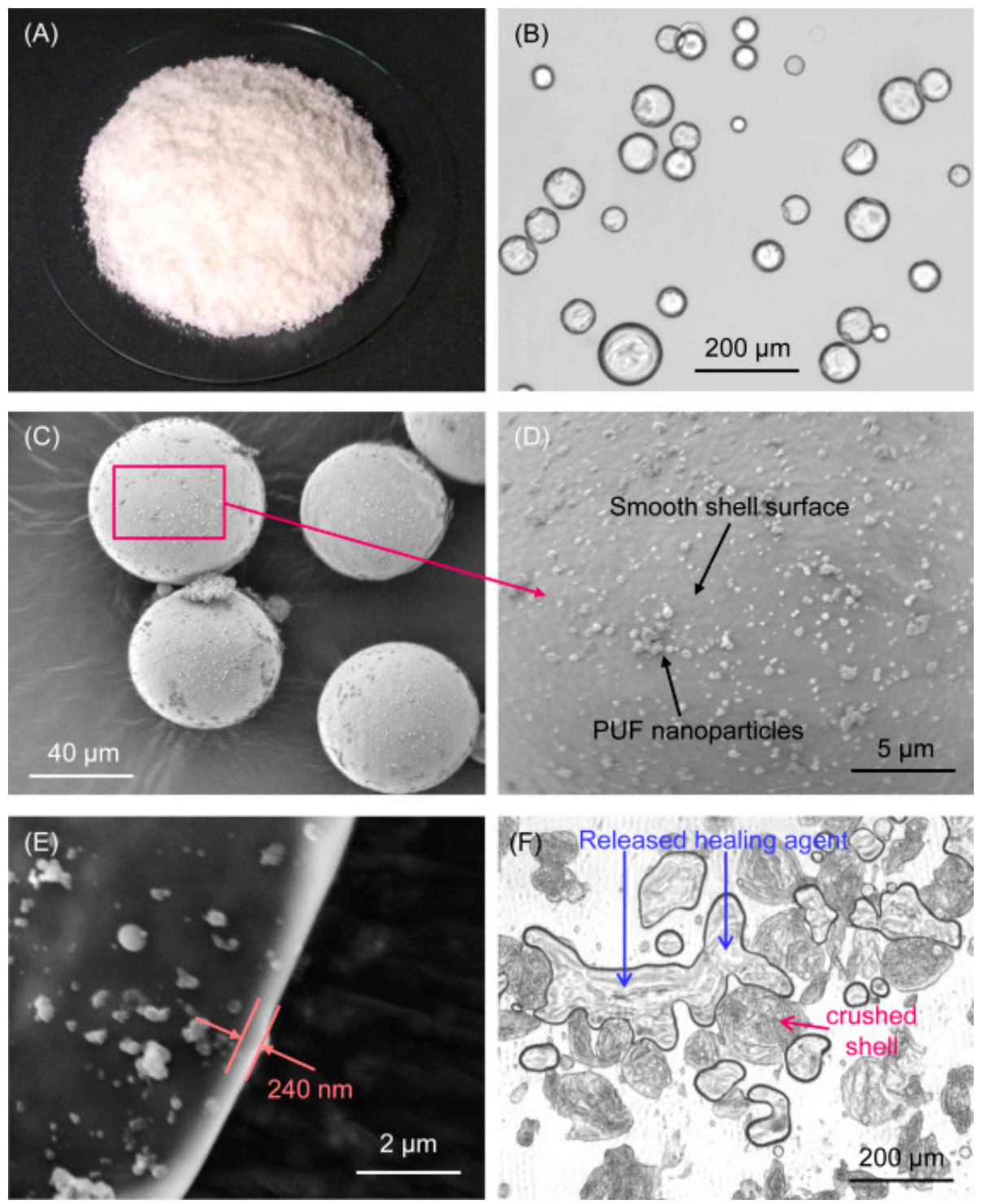

Figure 15. Microcapsules were prepared with a polymerizable TEGDMA-DHEPT healing liquid inside PUF shells. (A) Photo showing a pile of synthesized microcapsules. (B) Transmitting optical image showing the shell structure as a dark ring. (C) SEM image of typical microcapsules. (D) High-magnification SEM image of the shell surface showing nanoparticle deposits on an otherwise smooth shell surface. (E) High-magnification SEM image indicating the shell thickness. (F) Optical image of crushed microcapsules showing the released healing liquid films. Images from [111]. 


\section{Conclusions and Perspectives}

The emergence of new fillers has further enhanced the performance of DRCs. Compared to those used over the last decade, the new fillers show an improved bonding ability to the resin matrix. Moreover, the new fillers show a stronger ability for mechanical interlocking between the filler physical space and the resin matrix. This phenomenon is more prominent in porous materials, such as porous particles, mesoporous silica particles, and it is also present in other fillers with special shapes, such as UHA, fibrous fillers, and tetrapodlike whiskers. As well as in the improved chemical combination, core-sheath fillers have better bonding performance compared with the traditional filler. The shell with the external components will be adjusted according to the resin matrix chosen, such as glass vs. ZY@S, PAN vs. PAN-PMMA. In addition, the porosity of filler improves the drug-loading capacity, and the core-sheath structure enables the ability to control drug release.

In our search of review, the final physical properties of dental resin composites are greatly improved following the addition of morphology changed fillers. This improvement may be a result of the modified bonding capacity of the new fillers (e.g., the mechanical improvements of porous, mesoporous, and UHA fillers and the superiority of core-sheath fillers in chemical bonding). However, micro cracks still can be observed between the new morphology fillers and the resin matrix, some porous fillers still need more strength. Moreover, the core-sheath structure is a promising morphological feature, but preparation technology still needs to improve and innovate. It is these shortcomings that make the study of these fillers meaningful, which is also the significance of this work. Up to the present, we believe that the development of fillers may not be limited to the traditional morphology of granular and fibrous, or even the fusion of granular and fibrous types. New fillers, such as UHA and Tetrapod-like whiskers, may also be the focus of future research on fillers.

The ultimate goal of studying DRCs is to obtain a super excellent dental material for better oral service. At present, most of the current research on DRCs is focused on the matrix studying or strengthening comparison of several relatively single dental fillers, lacking comprehensive understanding, and longitudinal studies of the fillers. Moreover, interactions between two important components of DRCs, fillers, and matrix, are also of great importance. Hence, fillers need more historical reviews to get a new idea. The filler should be equivalent to the resin matrix, and fillers vs. resin matrix should be further considered. The interactions between fillers and the resin matrix should be continuously studied. Innovations in these areas are undisputedly the key to the development of truly high-performance DRCs to meet the ever-increasing future oral health needs.

Author Contributions: The manuscript was written through the contributions of all authors. Conceptualization, writing, editing, and reviewing: S.L.; reviewing, writing, and revising: J.L., H.Z., Y.L., W.L., H.S. and B.S. All authors have read and agreed to the published version of the manuscript.

Funding: This work was supported by the Key Research and Development Program of Shaanxi Province of China (2019SF-018).

Institutional Review Board Statement: Not applicable.

Informed Consent Statement: Not applicable.

Data Availability Statement: Data available in a publicly accessible repository. Data sharing not applicable to this article as no datasets were generated or analyzed during the current study.

Conflicts of Interest: The authors declare no conflict of interest.

\section{References}

1. Rasines Alcaraz, M.G. Direct composite resin fillings versus amalgam fillings for permanent posterior teeth. Cochrane Database Syst. Rev. 2014. [CrossRef] [PubMed]

2. Chen, H.; Wei, S.; Wang, R.; Zhu, M. Improving the Physical-Mechanical Property of Dental Composites by Grafting MethacrylatePolyhedral Oligomeric Silsesquioxane onto a Filler Surface. ACS Biomater. Sci. Eng. 2021, 7, 1428-1437. [CrossRef] 
3. Aminoroaya, A.; EsmaeelyNeisiany, R.; Nouri Khorasani, S.; Panahi, P.; Das, O.; Ramakrishna, S. A Review of Dental Composites: Methods of Characterizations. ACS Biomater. Sci. Eng. 2020, 6, 3713-3744. [CrossRef] [PubMed]

4. Zabrovsky, A.; Neeman Levy, T.; Bar-On, H.; Beyth, N.; Ben-Gal, G. Next generation of dentists moving to amalgam-free dentistry: Survey of posterior restorations teaching in North America. Eur. J. Dent. Educ. 2019, 23, 355-363. [CrossRef] [PubMed]

5. Verde, A.V.; Ramos, M.M.D.; Stoneham, A.M. Benefits in Cost and Reduced Discomfort of New Techniques of Minimally Invasive Cavity Treatment. J. Dent. Res. 2009, 88, 297-299. [CrossRef]

6. Weng, Y.; Howard, L.; Guo, X.; Chong, V.J.; Gregory, R.L.; Xie, D. A novel antibacterial resin composite for improved dental restoratives. J. Mater. Sci. Mater. Med. 2012, 23, 1553-1561. [CrossRef]

7. Pérez-Mondragón, A.A.; Cuevas-Suárez, C.E.; Trejo-Carbajal, N.; Piva, E.; da Fernandes Silva, A.; Herrera-González, A.M. Evaluation of monomers derived from resorcinol as eluents of bisphenol A glycidyl dimethacrylate for the formulation of dental composite resins. J. Appl. Polym. Sci. 2020, 137, 48576. [CrossRef]

8. He, J.; Garoushi, S.; Säilynoja, E.; Vallittu, P.K.; Lassila, L. The effect of adding a new monomer "Phene" on the polymerization shrinkage reduction of a dental resin composite. Dent. Mater. 2019, 35, 627-635. [CrossRef]

9. Bai, X.; Lin, C.; Wang, Y.; Ma, J.; Wang, X.; Yao, X.; Tang, B. Preparation of Zn doped mesoporous silica nanoparticles (Zn-MSNs) for the improvement of mechanical and antibacterial properties of dental resin composites. Dent. Mater. 2020, 36, 794-807. [CrossRef]

10. Herrera-González, A.M.; Pérez-Mondragón, A.A.; Cuevas-Suárez, C.E. Evaluation of bio-based monomers from isosorbide used in the formulation of dental composite resins. J. Mech. Behav. Biomed. Mater. 2019, 100, 103371. [CrossRef]

11. Kim, K.-H.; Ong, J.L.; Okuno, O. The effect of filler loading and morphology on the mechanical properties of contemporary composites. J. Prosthet. Dent. 2002, 87, 642-649. [CrossRef]

12. Wang, Y.; Zhu, M.; Zhu, X.X. Functional fillers for dental resin composites. Acta Biomater. 2021, 122, 50-65. [CrossRef] [PubMed]

13. Yang, D.-L.; Sun, Q.; Niu, H.; Wang, R.-L.; Wang, D.; Wang, J.-X. The properties of dental resin composites reinforced with silica colloidal nanoparticle clusters: Effects of heat treatment and filler composition. Compos. Part B Eng. 2020, 186, 107791. [CrossRef]

14. Maran, B.M.; de Geus, J.L.; Gutiérrez, M.F.; Heintze, S.; Tardem, C.; Barceleiro, M.O.; Reis, A.; Loguercio, A.D. Nanofilled/nanohybrid and hybrid resin-based composite in patients with direct restorations in posterior teeth: A systematic review and meta-analysis. J. Dent. 2020, 99, 103407. [CrossRef] [PubMed]

15. Wang, Y.; Hua, H.; Liu, H.; Zhu, M.; Zhu, X.X. Surface Modification of $\mathrm{ZrO}_{2}$ Nanoparticles and Its Effects on the Properties of Dental Resin Composites. ACS Appl. Bio Mater. 2020, 3, 5300-5309. [CrossRef]

16. Habib, E.; Wang, R.; Wang, Y.; Zhu, M.; Zhu, X.X. Inorganic Fillers for Dental Resin Composites: Present and Future. ACS Biomater. Sci. Eng. 2016, 2, 1-11. [CrossRef] [PubMed]

17. Randolph, L.D.; Palin, W.M.; Leloup, G.; Leprince, J.G. Filler characteristics of modern dental resin composites and their influence on physico-mechanical properties. Dent. Mater. 2016, 32, 1586-1599. [CrossRef] [PubMed]

18. Wang, R.; Zhang, M.; Liu, F.; Bao, S.; Wu, T.; Jiang, X.; Zhang, Q.; Zhu, M. Investigation on the physical-mechanical properties of dental resin composites reinforced with novel bimodal silica nanostructures. Mater. Sci. Eng. C 2015, 50, 266-273. [CrossRef]

19. Alvarado, J.A.; Maldonado, A.; Juarez, H.; Pacio, M. Synthesis of Colloidal ZnO Nanoparticles and Deposit of Thin Films by Spin Coating Technique. J. Nanomater. 2013, 2013, 903191. [CrossRef]

20. Shi, J.; Wang, Y.; Gao, Y.; Bai, H. Effects of coupling agents on the impact fracture behaviors of T-ZnOw/PA6 composites. Compos. Sci. Technol. 2008, 68, 1338-1347. [CrossRef]

21. Zhou, J.P.; Qiu, K.Q.; Fu, W.L. The Surface Modification of ZnOw and its Effect on the Mechanical Properties of Filled Polypropylene Composites. J. Compos. Mater. 2005, 39, 1931-1941. [CrossRef]

22. Chen, X.; Zhou, Z.; Lv, W.; Huang, T.; Hu, S. Preparation of core-shell structured T-ZnOw/polyaniline composites via graft polymerization. Mater. Chem. Phys. 2009, 115, 258-262. [CrossRef]

23. Cheng, L.; Zhou, X.; Zhong, H.; Deng, X.; Cai, Q.; Yang, X. NaF-loaded core-Shell PAN-PMMA nanofibers as reinforcements for Bis-GMA/TEGDMA restorative resins. Mater. Sci. Eng. C 2014, 34, 262-269. [CrossRef]

24. Wang, X.; Cai, Q.; Zhang, X.; Wei, Y.; Xu, M.; Yang, X.; Ma, Q.; Cheng, Y.; Deng, X. Improved performance of Bis-GMA/TEGDMA dental composites by net-like structures formed from $\mathrm{SiO} 2$ nanofiber fillers. Mater. Sci. Eng. C 2016, 59, 464-470. [CrossRef] [PubMed]

25. Hahnel, S.; Dowling, A.H.; El-Safty, S.; Fleming, G.J.P. The influence of monomeric resin and filler characteristics on the performance of experimental resin-based composites (RBCs) derived from a commercial formulation. Dent. Mater. 2012, 28, 416-423. [CrossRef] [PubMed]

26. Rüttermann, S.; Dluzhevskaya, I.; Großsteinbeck, C.; Raab, W.H.M.; Janda, R. Impact of replacing Bis-GMA and TEGDMA by other commercially available monomers on the properties of resin-based composites. Dent. Mater. 2010, 26, 353-359. [CrossRef]

27. Musanje, L.; Ferracane, J.L. Effects of resin formulation and nanofiller surface treatment on the properties of experimental hybrid resin composite. Biomaterials 2004, 25, 4065-4071. [CrossRef] [PubMed]

28. Bociong, K.; Szczesio, A.; Krasowski, M.; Sokolowski, J. The influence of filler amount on selected properties of new experimental resin dental composite. In Open Chemistry; Springer: Berlin, Germany, 2018; Volume 16, p. 905.

29. Ilie, N. Comparative Effect of Self- or Dual-Curing on Polymerization Kinetics and Mechanical Properties in a Novel, DentalResin-Based Composite with Alkaline Filler. Running Title: Resin-Composites with Alkaline Fillers. Materials 2018, 11, 108. [CrossRef] [PubMed] 
30. O'Brien, W.J. Dental Materials and Their Selection, 3rd ed.; Quintessence Publishing Co, Inc.: Berlin, German, 2002.

31. Watts, D.C. Radiopacity vs. composition of some barium and strontium glass composites. J. Dent. 1987, 15, 38-43. [CrossRef]

32. Stencel, R.; Kasperski, J.; Pakieła, W.; Mertas, A.; Bobela, E.; Barszczewska-Rybarek, I.; Chladek, G. Properties of Experimental Dental Composites Containing Antibacterial Silver-Releasing Filler. Materials 2018, 11, 1031. [CrossRef]

33. Chiari, M.D.S.; Rodrigues, M.C.; Xavier, T.A.; de Souza, E.M.N.; Arana-Chavez, V.E.; Braga, R.R. Mechanical properties and ion release from bioactive restorative composites containing glass fillers and calcium phosphate nano-structured particles. Dent. Mater. 2015, 31, 726-733. [CrossRef] [PubMed]

34. Söderholm, K.J. Degradation of Glass Filler in Experimental Composites. J. Dent. Res. 1981, 60, 1867-1875. [CrossRef] [PubMed]

35. Soderholm, K.J.M.; Mukherjee, R.; Longmate, J. Filler Leachability of Composites Stored in Distilled Water or Artificial Saliva. J. Dent. Res. 1996, 75, 1692-1699. [CrossRef] [PubMed]

36. Soderholm, K.J.M. Leaking of Fillers in Dental Composites. J. Dent. Res. 1983, 62, 126-130. [CrossRef]

37. Söderholm, K.J.; Zigan, M.; Ragan, M.; Fischlschweiger, W.; Bergman, M. Hydrolytic Degradation of Dental Composites. J. Dent. Res. 1984, 63, 1248-1254. [CrossRef]

38. Yao, S.; Li, T.; Zhou, C.; Weir, M.D.; Melo, M.A.S.; Tay, F.R.; Lynch, C.D.; Imazato, S.; Wu, J.; Xu, H.H.K. Novel antibacterial and therapeutic dental polymeric composites with the capability to self-heal cracks and regain mechanical properties. Eur. Polym. J. 2020, 129, 109604. [CrossRef]

39. Miao, X.; Li, Y.; Zhang, Q.; Zhu, M.; Wang, H. Low shrinkage light curable dental nanocomposites using $\mathrm{SiO}_{2} \mathrm{microspheres} \mathrm{as}$ fillers. Mater. Sci. Eng. C 2012, 32, 2115-2121. [CrossRef]

40. Masalov, V.M.; Sukhinina, N.S.; Kudrenko, E.A.; Emelchenko, G.A. Mechanism of formation and nanostructure of Stöber silica particles. Nanotechnology 2011, 22, 275718. [CrossRef] [PubMed]

41. Drummond, J.L. Degradation, Fatigue, and Failure of Resin Dental Composite Materials. J. Dent. Res. 2008, 87, 710-719. [CrossRef]

42. Zhang, M.; Matinlinna, J.P. E-Glass Fiber Reinforced Composites in Dental Applications. Silicon 2012, 4, 73-78. [CrossRef]

43. Zheng, Y.; Ning, R.; Zheng, Y. Study of SiO2 Nanoparticles on the Improved Performance of Epoxy and Fiber Composites. J. Reinf. Plast. Compos. 2005, 24, 223-233. [CrossRef]

44. Beun, S.; Glorieux, T.; Devaux, J.; Vreven, J.; Leloup, G. Characterization of nanofilled compared to universal and microfilled composites. Dent. Mater. 2007, 23, 51-59. [CrossRef] [PubMed]

45. Arcís, R.W.; López-Macipe, A.; Toledano, M.; Osorio, E.; Rodríguez-Clemente, R.; Murtra, J.; Fanovich, M.A.; Pascual, C.D. Mechanical properties of visible light-cured resins reinforced with hydroxyapatite for dental restoration. Dent. Mater. 2002, 18, 49-57. [CrossRef]

46. Hicks, J.; Garcia-Godoy, F.; Flaitz, C. Biological factors in dental caries: Role of saliva and dental plaque in the dynamic process of demineralization and remineralization (part 1). J. Clin. Pediatr. Dent. 2003, 28, 47-52. [CrossRef] [PubMed]

47. Abdulrahman, A.B.; Anmar, A.K.; Denise, H.; Michael, D.W.; Hockin, H.K.X.; Mary Anne, S.M. Toward dental caries: Exploring nanoparticle-based platforms and calcium phosphate compounds for dental restorative materials. Bioact. Mater. 2019, 4, 43-55.

48. Li, S.; Zhang, L.; Kim, J.; Pan, M.; Shi, Z.; Zhang, J. Synthesis of carbon-supported binary FeCo-N non-noble metal electrocatalysts for the oxygen reduction reaction. Electrochim. Acta 2010, 55, 7346-7353. [CrossRef]

49. Liu, F.; Jiang, X.; Zhang, Q.; Zhu, M. Strong and bioactive dental resin composite containing poly(Bis-GMA) grafted hydroxyapatite whiskers and silica nanoparticles. Compos. Sci. Technol. 2014, 101, 86-93. [CrossRef]

50. Liu, F.; Wang, R.; Cheng, Y.; Jiang, X.; Zhang, Q.; Zhu, M. Polymer grafted hydroxyapatite whisker as a filler for dental composite resin with enhanced physical and mechanical properties. Mater. Sci. Eng. C 2013, 33, 4994-5000. [CrossRef] [PubMed]

51. Zhang, H.; Darvell, B.W. Mechanical properties of hydroxyapatite whisker-reinforced bis-GMA-based resin composites. Dent. Mater. 2012, 28, 824-830. [CrossRef]

52. Chen, L.; Yu, Q.; Wang, Y.; Li, H. BisGMA/TEGDMA dental composite containing high aspect-ratio hydroxyapatite nanofibers. Dent. Mater. 2011, 27, 1187-1195. [CrossRef]

53. Taheri, M.M.; Abdul Kadir, M.R.; Shokuhfar, T.; Hamlekhan, A.; Shirdar, M.R.; Naghizadeh, F. Fluoridated hydroxyapatite nanorods as novel fillers for improving mechanical properties of dental composite: Synthesis and application. Mater. Des. 2015, 82, 119-125. [CrossRef]

54. Liu, F.; Sun, B.; Jiang, X.; Aldeyab, S.S.; Zhang, Q.; Zhu, M. Mechanical properties of dental resin/composite containing urchin-like hydroxyapatite. Dent. Mater. 2014, 30, 1358-1368. [CrossRef]

55. Suzuki, S.; Ori, T.; Saimi, Y. Effects of filler composition on flexibility of microfilled resin composite. J. Biomed. Mater. Res. Part B Appl. Biomater. 2005, 74, 547-552. [CrossRef]

56. Yukitani, W.; Hasegawa, T.; Itoh, K.; Hisamitsu, H.; Wakumoto, S.J.O.D. Marginal adaptation of dental composites containing prepolymerized filler. Oper. Dent. 1997, 22, 242-248. [PubMed]

57. Blackham, J.T.; Vandewalle, K.S.; Lien, W. Properties of Hybrid Resin Composite Systems Containing Prepolymerized Filler Particles. Oper. Dent. 2009, 34, 697-702. [CrossRef] [PubMed]

58. Nee, A.Y.C. Handbook of Manufacturing Engineering and Technology; Springer: Berlin, Germany, 2015.

59. Garoushi, S.; Säilynoja, E.; Vallittu, P.K.; Lassila, L. Physical properties and depth of cure of a new short fiber reinforced composite. Dent. Mater. 2013, 29, 835-841. [CrossRef] [PubMed]

60. Krause, W.R.; Park, S.-H.; Straup, R.A. Mechanical properties of BIS-GMA resin short glass fiber composites. J. Biomed. Mater. Res. 1989, 23, 1195-1211. [CrossRef] [PubMed] 
61. Ruddell, D.E.; Maloney, M.M.; Thompson, J.Y. Effect of novel filler particles on the mechanical and wear properties of dental composites. Dent. Mater. 2002, 18, 72-80. [CrossRef]

62. Vallittu, P.K. High-aspect ratio fillers: Fiber-reinforced composites and their anisotropic properties. Dent. Mater. 2015, 31, 1-7. [CrossRef]

63. Xu, H.H.K.; Martin, T.A.; Antonucci, J.M.; Eichmiller, E.C. Ceramic Whisker Reinforcement of Dental Resin Composites. J. Dent. Res. 1999, 78, 706-712. [CrossRef]

64. Debnath, S.; Ranade, R.; Wunder, S.L.; McCool, J.; Boberick, K.; Baran, G. Interface effects on mechanical properties of particlereinforced composites. Dent. Mater. 2004, 20, 677-686. [CrossRef]

65. Garoushi, S.; Vallittu, P.K.; Lassila, L.V.J. Short glass fiber reinforced restorative composite resin with semi-inter penetrating polymer network matrix. Dent. Mater. 2007, 23, 1356-1362. [CrossRef] [PubMed]

66. Garoushi, S.; Lassila, L.V.J.; Tezvergil, A.; Vallittu, P.K. Load bearing capacity of fibre-reinforced and particulate filler composite resin combination. J. Dent. 2006, 34, 179-184. [CrossRef] [PubMed]

67. Xu, H.H.K.; Sun, L.; Weir, M.D.; Antonucci, J.M.; Takagi, S.; Chow, L.C.; Peltz, M. Nano DCPA-Whisker Composites with High Strength and Ca and PO4 Release. J. Dent. Res. 2006, 85, 722-727. [CrossRef] [PubMed]

68. Xu, H.H.K.; Quinn, J.B.; Smith, D.T.; Giuseppetti, A.A.; Eichmiller, F.C. Effects of different whiskers on the reinforcement of dental resin composites. Dent. Mater. 2003, 19, 359-367. [CrossRef]

69. Lassila, L.; Garoushi, S.; Vallittu, P.K.; Säilynoja, E. Mechanical properties of fiber reinforced restorative composite with two distinguished fiber length distribution. J. Mech. Behav. Biomed. Mater. 2016, 60, 331-338. [CrossRef]

70. Lastumäki, T.M.; Lassila, L.V.; Vallittu, P.K. Flexural properties of the bulk fiber-reinforced composite DC-tell used in fixed partial dentures. Int. J. Prosthodont. 2001, 14, 22-26.

71. Liu, Y.; Sagi, S.; Chandrasekar, R.; Zhang, L.; Hedin, N.E.; Fong, H. Preparation and Characterization of Electrospun SiO2 Nanofibers. J. Nanosci. Nanotechnol. 2008, 8, 1528-1536. [CrossRef]

72. Xu, H.H.K.; Quinn, J.B.; Smith, D.T.; Antonucci, J.M.; Schumacher, G.E.; Eichmiller, F.C. Dental resin composites containing silica-fused whiskers-Effects of whisker-to-silica ratio on fracture toughness and indentation properties. Biomaterials 2002, 23, 735-742. [CrossRef]

73. Garoushi, S.; Vallittu, P.K.; Watts, D.C.; Lassila, L.V.J. Polymerization shrinkage of experimental short glass fiber-reinforced composite with semi-inter penetrating polymer network matrix. Dent. Mater. 2008, 24, 211-215. [CrossRef]

74. Bijelic-Donova, J.; Garoushi, S.; Vallittu, P.K.; Lassila, L.V.J. Mechanical properties, fracture resistance, and fatigue limits ofshort fiber reinforced dental composite resin. J. Prosthet. Dent. 2016, 115, 95-102. [CrossRef]

75. Guo, G.; Fan, Y.; Zhang, J.-F.; Hagan, J.L.; Xu, X. Novel dental composites reinforced with zirconia-Silica ceramic nanofibers. Dent. Mater. 2012, 28, 360-368. [CrossRef]

76. Gao, Y.; Sagi, S.; Zhang, L.; Liao, Y.; Cowles, D.M.; Sun, Y.; Fong, H. Electrospun nano-scaled glass fiber reinforcement of bis-GMA/TEGDMA dental composites. J. Appl. Polym. Sci. 2008, 110, 2063-2070. [CrossRef]

77. Tian, M.; Gao, Y.; Liu, Y.; Liao, Y.; Hedin, N.E.; Fong, H. Fabrication and evaluation of Bis-GMA/TEGDMA dental resins/composites containing nano fibrillar silicate. Dent. Mater. 2008, 24, 235-243. [CrossRef] [PubMed]

78. Fong, H. Electrospun nylon 6 nanofiber reinforced BIS-GMA/TEGDMA dental restorative composite resins. Polymer 2004, 45, 2427-2432. [CrossRef]

79. Zhu, J.; Peng, H.; Rodriguez-Macias, F.; Margrave, J.L.; Khabashesku, V.N.; Imam, A.M.; Lozano, K.; Barrera, E.V. Reinforcing Epoxy Polymer Composites Through Covalent Integration of Functionalized Nanotubes. Adv. Funct. Mater. 2004, 14, 643-648. [CrossRef]

80. Zhang, F.; Xia, Y.; Xu, L.; Gu, N. Surface modification and microstructure of single-walled carbon nanotubes for dental resin-based composites. J. Biomed. Mater. Res. Part B Appl. Biomater. 2008, 86, 90-97. [CrossRef]

81. Borges, A.L.S.; Münchow, E.A.; de Oliveira Souza, A.C.; Yoshida, T.; Vallittu, P.K.; Bottino, M.C. Effect of random/aligned nylon-6/MWCNT fibers on dental resin composite reinforcement. J. Mech. Behav. Biomed. Mater. 2015, 48, 134-144. [CrossRef]

82. Chen, Q.; Zhao, Y.; Wu, W.; Xu, T.; Fong, H. Fabrication and evaluation of Bis-GMA/TEGDMA dental resins/composites containing halloysite nanotubes. Dent. Mater. 2012, 28, 1071-1079. [CrossRef]

83. Cunha, D.A.; Rodrigues, N.S.; Souza, L.C.; Lomonaco, D.; Rodrigues, F.P.; Degrazia, F.W.; Collares, F.M.; Sauro, S.; Saboia, V.P.A. Physicochemical and Microbiological Assessment of an Experimental Composite Doped with Triclosan-Loaded Halloysite Nanotubes. Materials 2018, 11, 1080. [CrossRef]

84. Horcajada, P.; Chalati, T.; Serre, C.; Gillet, B.; Sebrie, C.; Baati, T.; Eubank, J.F.; Heurtaux, D.; Clayette, P.; Kreuz, C.; et al. Porous metal-Organic-framework nanoscale carriers as a potential platform for drug deliveryand imaging. Nat. Mater. $2009,9,172$. [CrossRef]

85. Salerno, M.; Loria, P.; Matarazzo, G.; Tomè, F.; Diaspro, A.; Eggenhöffner, R. Surface Morphology and Tooth Adhesion of a Novel Nanostructured Dental Restorative Composite. Materials 2016, 9, 203. [CrossRef] [PubMed]

86. Zandinejad, A.A.; Atai, M.; Pahlevan, A. The effect of ceramic and porous fillers on the mechanical properties of experimental dental composites. Dent. Mater. 2006, 22, 382-387. [CrossRef] [PubMed]

87. Atai, M.; Pahlavan, A.; Moin, N. Nano-porous thermally sintered nano silica as novel fillers for dental composites. Dent. Mater. 2012, 28, 133-145. [CrossRef] 
88. Liu, Y.; Tan, Y.; Lei, T.; Xiang, Q.; Han, Y.; Huang, B. Effect of porous glass-ceramic fillers on mechanical properties of light-cured dental resin composites. Dent. Mater. 2009, 25, 709-715. [CrossRef] [PubMed]

89. Rapp, M.; Thomspon, J.; Bayne, S.; Rathbun, K. Development of Pre-Polymerized Branched-Fiber Filler Particles. In Journal of Dental Research; Amer Assoc Dental Research: Alexandria, VA, USA, 1998; p. 170.

90. Jandt, K.D.; Al-Jasser, A.M.O.; Al-Ateeq, K.; Vowles, R.W.; Allen, G.C. Mechanical properties and radiopacity of experimental glass-silica-metal hybrid composites. Dent. Mater. 2002, 18, 429-435. [CrossRef]

91. Wang, R.; Habib, E.; Zhu, X.X. Synthesis of wrinkled mesoporous silica and its reinforcing effect for dental resin composites. Dent. Mater. 2017, 33, 1139-1148. [CrossRef]

92. Rodríguez, H.A.; Giraldo, L.F.; Casanova, H. Formation of functionalized nanoclusters by solvent evaporation and their effect on the physicochemical properties of dental composite resins. Dent. Mater. 2015, 31, 789-798. [CrossRef]

93. Mitra, S.B.; Wu, D.; Holmes, B.N. An application of nanotechnology in advanced dental materials. J. Am. Dent. Assoc. 2003, 134, 1382-1390. [CrossRef]

94. Curtis, A.R.; Palin, W.M.; Fleming, G.J.P.; Shortall, A.C.C.; Marquis, P.M. The mechanical properties of nanofilled resin-based composites: The impact of dry and wet cyclic pre-loading on bi-axial flexure strength. Dent. Mater. 2009, 25, 188-197. [CrossRef]

95. Curtis, A.R.; Palin, W.M.; Fleming, G.J.P.; Shortall, A.C.C.; Marquis, P.M. The mechanical properties of nanofilled resin-based composites: Characterizing discrete filler particles and agglomerates using a micromanipulation technique. Dent. Mater. 2009, 25, 180-187. [CrossRef] [PubMed]

96. Wang, R.; Bao, S.; Liu, F.; Jiang, X.; Zhang, Q.; Sun, B.; Zhu, M. Wear behavior of light-cured resin composites with bimodal silica nanostructures as fillers. Mater. Sci. Eng. C 2013, 33, 4759-4766. [CrossRef]

97. Zhou, Z.; Deng, H.; Yi, J.; Liu, S. A new method for preparation of zinc oxide whiskers. Mater. Res. Bull. 1999, $34,1563-1567$. [CrossRef]

98. Li, S.; Zhang, J.-F.; Chen, J.; Zhao, Y.; Zhao, X.; Xu, X. Core-sheath zirconia/silica microfibers for dental composites reinforcement. Mater. Lett. 2015, 142, 204-206. [CrossRef]

99. Glassflake Ltd. What is Glassflake? Available online: https:/ / www.glassflake.com/what-is-glassflake/ (accessed on 7 June 2021 ).

100. Akiko, S.; Fumio, W.; Juichi, I.N.O.; Junko, M.; Motohiro, U.O. Application of flake shaped glass (Glass Flake ${ }^{\circledR}$ ) filler for dental composite resin. J. Ceram. Soc. Jpn. 2010, 118, 425.

101. Mohseni, M.; Atai, M.; Sabet, A.; Beigi, S. Effect of plate-like glass fillers on the mechanical properties of dental nanocomposites. Iran. Polym. J. 2016, 25, 129. [CrossRef]

102. Benedikt, S.; Sebastian, L.; Thorsten, G.; Dieter, B. Optical and Mechanical Properties of Highly Transparent Glass-Flake Composites. J. Compos. Sci. 2019, 3, 101.

103. Amini, A.; Khavari, A.; Molter, C.; Ehrlicher, A.J. A bioinspired optically transparent tough glass composite. arXiv 2020, arXiv:2003.13863.

104. Wu, J.; Xie, X.; Zhou, H.; Tay, F.R.; Weir, M.D.; Melo, M.A.S.; Oates, T.W.; Zhang, N.; Zhang, Q.; Xu, H.H.K. Development of a new class of self-healing and therapeutic dental resins. Polym. Degrad. Stab. 2019, 163, 87-99. [CrossRef]

105. Zhu, D.Y.; Rong, M.Z.; Zhang, M.Q. Self-healing polymeric materials based on microencapsulated healing agents: From design to preparation. Prog. Polym. Sci. 2015, 49, 175-220. [CrossRef]

106. Bekas, D.G.; Tsirka, K.; Baltzis, D.; Paipetis, A.S. Self-healing materials: A review of advances in materials, evaluation, characterization and monitoring techniques. Compos. Part B 2016, 87, 92-119. [CrossRef]

107. Then, S.; Neon, G.S.; Abu Kasim, N.H. Performance of Melamine Modified Urea-Formaldehyde Microcapsules in a Dental Host Material. J. Appl. Polym. Sci. 2011, 122, 2557-2562. [CrossRef]

108. Wertzberger, B.E.; Steere, J.T.; Pfeifer, R.M.; Nensel, M.A.; Latta, M.A.; Gross, S.M. Physical Characterization of a Self-Healing Dental Restorative Material. J. Appl. Polym. Sci. 2010, 118, 428-434. [CrossRef]

109. Yahyazadehfar, M.; Huyang, G.; Wang, X.; Fan, Y.; Arola, D.; Sun, J. Durability of self-healing dental composites: A comparison of performance under monotonic and cyclic loading. Mater. Sci. Eng. C 2018, 93, 1020-1026. [CrossRef] [PubMed]

110. Huyang, G.; Debertin, A.E.; Sun, J. Design and development of self-healing dental composites. Mater. Des. 2016, 94, 295-302. [CrossRef] [PubMed]

111. Wu, J.; Weir, M.D.; Zhang, Q.; Zhou, C.; Melo, M.A.S.; Xu, H.H.K. Novel self-healing dental resin with microcapsules of polymerizable triethylene glycol dimethacrylate and N,N-dihydroxyethyl-p-toluidine. Dent. Mater. 2016, 32, 294-304. [CrossRef] [PubMed] 